Article

\title{
Analysis of Nanofluids Behavior in Concentrated Solar Power Collectors with Organic Rankine Cycle
}

\author{
Samuel Sami ${ }^{1,2}$ \\ 1 Research Center for Renewable Energy, Catholic University of Cuenca, Cuenca 010151, Ecuador; \\ dr.ssami@transpacenergy.com \\ 2 TransPacific Energy, Inc., Las Vegas, NV 89183, USA
}

Received: 14 June 2019; Accepted: 8 July 2019; Published: 16 July 2019

\begin{abstract}
In this paper, the performance of nanofluids in a Parabolic Trough Concentrating Solar Collector (CSP)-based power generation plant, an Organic Rankine Cycle (ORC), and a Thermal Energy Storage (TES) system is studied. This study is intended to investigate the enhancement effect and characteristics of nanofluids $\mathrm{Al}_{2} \mathrm{O}_{3}, \mathrm{CuO}, \mathrm{Fe}_{3} \mathrm{O}_{4}$ and $\mathrm{SiO}_{2}$ in integrated concentrating solar power (CSP) with ORC, and TES under different solar radiations, angles of incidence, and different nanofluid concentrations. The refrigerant mixture used in the ORC loop to enhance the ORC efficiency is an environmentally sound quaternary mixture composed of R134a, R245fa, R125, R236fa. The results showed that the power absorbed, and power collected by the CSP collector and thermal energy stored in the storage tank are enhanced with the increase of the solar radiation. It was also found that the CSP hybrid system efficiency has been enhanced mainly by the increase of the solar radiation and higher nanofluid concentrations over the thermal oil as base fluid. Also, the study concludes that the nanofluid $\mathrm{CuO}$ outperforms the other nanofluids- $\mathrm{Al}_{2} \mathrm{O}_{3}, \mathrm{Fe}_{3} \mathrm{O}_{4}$ and $\mathrm{SiO}_{2}$-and has the highest CSP solar collector performance compared to the other nanofluids and thermal oil base fluid under study at similar conditions. Finally, it was found that the model's prediction compares fairly with data reported in the literature; however, some discrepancies exist between the model's prediction and the experimental data.
\end{abstract}

Keywords: CSP solar collectors; nanofluids; Organic Rankine Cycle; modelling; simulation and model's validation

\section{Introduction}

Solar energy can be utilized to produce both electricity and heat. Concentrated solar power collectors (CSPs) have received significant attention for their electricity generation capability. Thermal storage integrated CSPs overcome the intermittency of solar radiation. The thermo-physical properties of the heat transfer fluids (HTF) and the thermal energy storage (TES) materials are key to enhancing the system efficiency. Molten salts, such as alkali nitrates and alkali carbonates, are considered as alternatives to conventional HTF in CSP. However, the heat capacity of the molten salts is lower than that of conventional HTF.

Reviews of different concentrated solar power (CSP) collectors' applications have been available for several decades [1-7]. However, a possible improvement of CSP technologies can be realized through integration into a hybrid system that uses a CSP-Organic Rankine Cycle ORC system. This simultaneously provides electricity and heat [8-39].

In general, the CSP power generation systems use solar concentrators to focus solar radiation onto a receiver that carries a heat transfer fluid which is heated to a high temperature due to highly concentrated solar radiation. Generally, in most CSP plants, the heat transfer fluid is thermal oil. This heat transfer fluid goes to a conventional steam turbine, using water as coolant or an Organic 
Rankine Turbine generator (ORC) using refrigerant, where electricity is generated [1,7]. Thermal energy storage is an integral part of a CSP plant in order to overcome the intermittency of solar radiations for continuous production of power during the night and on cloudy days [8,9].

Nanofluid is a mixture of an HTF and nanoparticles and can be used to enhance the thermo-physical properties of HTF. Recently, it was proposed in references [10-18] to nanofluids as a heat transfer fluid in solar power collectors, and to investigate their optical properties, which are essential to the phenomenon of direct energy absorption. The results reported in these references showed that the maximum allowable temperature at which the absorption coefficient does not change significantly is as high as $500^{\circ} \mathrm{C}$. This makes metal-oxide nanoparticles suitable for use at very high temperatures in heat transfer fluids in CSP plants.

Heat transfer fluids with nanoparticles provide significant benefits in CSP solar power plants because of the enhancement of heat transfer, thermodynamic and thermophysical properties in absorbing heat induced by solar radiation. Enhanced heat transfer by the use nanofluids yields improvement to the receiver performance and absorption efficiency that may reduce the number of CSP collectors required to produce power using the basis fluid as thermal oil [28-35].

It has been shown theoretically and experimentally that, in low-temperature solar collectors at around $100{ }^{\circ} \mathrm{C}$, efficiency can be improved by using nanofluids [10,11]. A paper was presented by Calise and Vanoli [12] on the design procedure and a simulation model of a novel concentrating PVT collector. The model considered a parabolic trough concentrator and a linear triangular receiver. This model was based on zero-dimensional energy balances. The simulation model calculated the temperatures of the main components of the system and the main energy flows. The results showed that the performance of the system is excellent even when the fluid temperature is very high $\left(>100^{\circ} \mathrm{C}\right)$.

Bozorgan and Shafahi [13] presented a paper review on nanofluid as a heat transfer absorber fluid to enhance heat transfer in solar devices. This review summarized the research done in recent years on the nanofluids' applications in solar thermal engineering systems. The review article provided comprehensive information for the design of a solar thermal system working at the different operating conditions.

The enhancement of the thermal properties of various high-temperature nanofluids for solar thermal energy storage application in concentrating solar power (CSP) systems, the thermo-physical properties of the heat transfer fluids (HTF), and the thermal energy storage (TES) materials were studied and presented by reference [14]. In this study, silica $\left(\mathrm{SiO}_{2}\right)$ and alumina $\left(\mathrm{Al}_{2} \mathrm{O}_{3}\right)$ nanoparticles, as well as carbon nanotubes (CNT), were dispersed into a molten salt and a commercially available HTF. Dimensional analyses and computer simulations were performed to predict the enhancement of thermal properties of the nanofluids.

A model was presented by Saadatfar [18] for the analysis of thermodynamic cycle of the solar thermal production of power, heating and cooling utilizing nanofluid as a working fluid in Organic Rankine Cycle. The initial studies in reference [18] were performed with silver-nano pentane as a working fluid in the cycle. An available modeling program was used by this reference to model and investigate the performance of the system with nano organic fluid. This paper concluded that under optimum conditions, the thermodynamic efficiencies were higher than those obtained from the base fluid.

Reference [19] reported and analyzed high-temperature parabolic trough collectors (PTC) coupled with an Organic Rankine Cycle (ORC) to carry out optimization at both levels: financially and energetically. They investigated the solar field, the storage tank and the ORC module under many conditions of collecting solar areas and storage tank volumes. They also presented an economic comparison for different commercial solar collectors.

Adnan Alashkar and Mohamed Gadall [20] studied the performance of Parabolic Trough Solar Collector (PTSC)-based power generation plant, the effect of adding an Organic Rankine Cycle (ORC), and a Thermal Energy Storage (TES) system and the most efficient fluid on the performance and financial metrics of the PTSC-power plant. The simulation results of this paper showed that Benzene is 
the most efficient organic fluid, having the highest thermal and exergetic efficiency, and the lowest pumping power when compared to other organic fluids. Finally, thermodynamic modeling of ORC was reported in the literature by Saloux et al. [21], Sami [22,23], and Jo-ao [24] where low- and high-grade waste heat is converted into power.

In this paper, we present a numerical model to simulate and study the behavior of heat transfer fluid with different nanofluids circulating in the parabolic trough solar collector loop to drive an Organic Rankine Cycle with patent quaternary refrigerant mixture, under different solar radiations. The model is based upon the mass and energy equations written for the heat transfer fluid with nanofluids. These equations were integrated and solved to predict the behavior of the parabolic trough collectors (PTC) coupled with an Organic Rankine Cycle (ORC) under different operating conditions such as solar radiations, nanofluid flow rates, ambient temperatures, and various volumetric nanofluid concentrations. This study is intended to investigate the enhancement effect and characteristics of nanofluids $\mathrm{Al}_{2} \mathrm{O}_{3}, \mathrm{CuO}, \mathrm{Fe}_{3} \mathrm{O}_{4}$ and $\mathrm{SiO}_{2}$ in an integrated concentrating solar power (CSP) with ORC, and TES under different solar radiations, angle of incidence, and different nanofluids concentrations. Also, the objectives of this study are to investigate impact of the nanofluids $\mathrm{Al}_{2} \mathrm{O}_{3}, \mathrm{Fe}_{3} \mathrm{O}_{4}, \mathrm{CuO}$ and $\mathrm{SiO}_{2}$ on the CSP solar collector performance compared to thermal oil base fluid under study at similar conditions. This research represents a significant contribution to the nanofluid science where nanofluid are nanofluids are used to enhance performance of CSP solar collectors and integrated ORCs compared to thermal oil as base heat transfer fluid.

\section{Mathematical Model}

The mathematical model was established based on the mass and energy equations written to describe the behavior the nanofluids driving an Organic Rankine Cycle, ORC, with a refrigerant mixture as shown in Figure 1. This figure depicts the proposed CPS system. The CPS thermal loop is composed of a CPS solar collector, thermal storage tank, and pump, as well as the waste heat boiler of the ORC. The solar radiation is absorbed by the CSP solar collector and converted into thermal energy that heats up the nanofluids and thermal oil circulating in the thermal oil/storage tank loop. The thermal oil is the base fluid heat transport fluid with nanofluids is used to drive the ORC circuit.

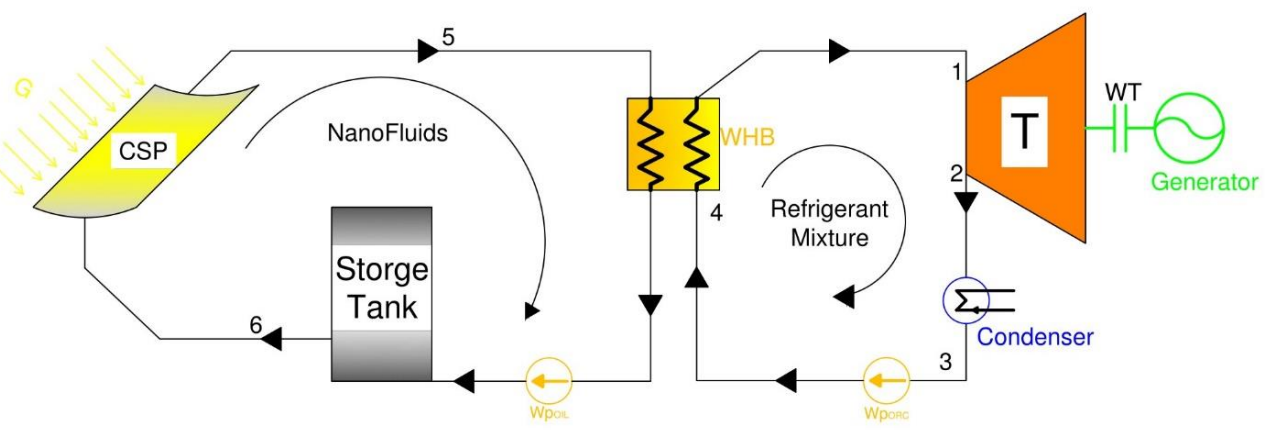

Figure 1. Flow diagram of the proposed system.

The thermal storage tank is used to store thermal energy, and during the intermittent solar radiation periods, it supplies heat to the ORC waste heat boiler. In the ORC circuit, the thermal heat absorbed evaporates the refrigerant mixture that drives the turbine. In the turbine, the thermal energy is converted into kinetic energy and produces power at the turbine shaft and the generator. The low-pressure vapor is condensed in the condenser into liquid and pumped back to the waste heat boiler. The refrigerant mixture used in the ORC loop is an environmentally sound quaternary mixture composed of R134a, R245fa, R125, R236fa [23]. Thermodynamic and thermophysical properties were obtained at REFPROP [27]. Figure 2 depicts the thermodynamic properties and the pressure-enthalpy diagram of the mixture R134a, R245fa, R125, R236fa, where it is quite clear that one of the most 
important characteristics is the variable saturation temperature and glide temperature. This feature is pivotal in enhancing the Organic Rankine Cycle efficiency.

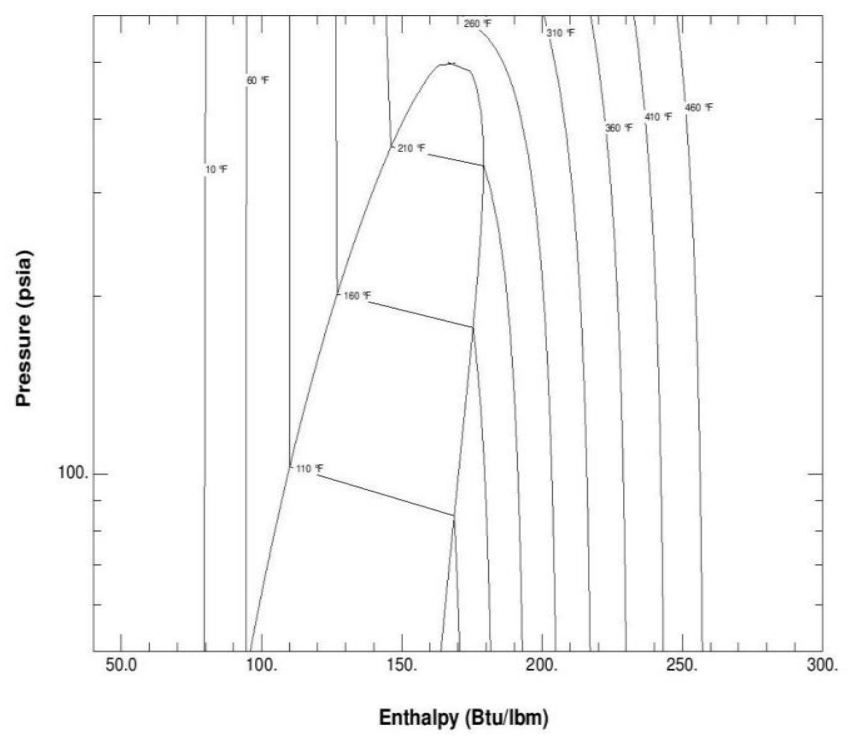

Figure 2. P-H diagram for the mixture R134a, R245fa, R125, R236fa.

In the following sections, the different equations of mass and energy are presented. It is assumed in the model that the nanofluid is homogeneous, isotropic, incompressible, and Newtonian; that inlet velocity and inlet temperature are constant; and that the thermophysical properties of the nanofluids are constant. In the following, the conservation mass and energy equations and heat transfer equations are written and presented for each element of the nanofluids.

\subsection{CSP Solar Collector Model}

The power absorbed from solar radiation by the CSP solar collector can be determined by the following [3-6,23];

$$
P_{a b s}=D I N * \cos \theta * \eta_{o p t} * I A M * R_{s} * E_{L} * S F_{\text {Avail }}
$$

where:

DNI: Solar radiation $\left(\mathrm{w} / \mathrm{m}^{2}\right)$

$\Theta$ : Angle of incidence

$\eta_{\text {opt }}$ : Optical efficiency

IAM: Incidence angle modifier.

$R_{s}$ : Row shadow

$E_{l}$ : End losses

$S F_{\text {Aval }}$ : Solar field available

The CSP collected power is given by;

$$
P_{\text {collector }}=P_{\text {abs }}-P_{\text {losscol }}-P_{\text {losspip }}
$$

where:

$P_{a b s}$ : Collector power absorbed by CSP defined in Equation (1)

$P_{\text {losscol: }}$ Collector thermal losses of the CSP.

$P_{\text {losspip: }}$ solar field piping losses. 
The collected power calculated in Equation (2) is transferred to the heat transfer fluid, thermal oil, and nanofluids loop. It is also assumed that this thermal energy will be accumulated in the thermal storage tank that supplies the thermal energy to drive the ORC cycle.

The CSP collector thermal losses are calculated by Equations (3)-(5);

$$
\begin{gathered}
P_{\text {losscol }}=L_{c 1}+L_{c 2} \\
L_{c 1}=a_{2} \Delta \mathrm{T}_{1}^{2}+a_{1} \Delta \mathrm{T}_{1}-a_{0} \\
L_{c 2}=\left(b_{2} \Delta \mathrm{T}_{1}^{2}+b_{1} \Delta \mathrm{T}_{1}-b_{0}\right)\left(\frac{D N I}{900}\right) \cos \theta
\end{gathered}
$$

Readers interested in the detailed calculation of the collector thermal losses are advised to consult references [3-6,23].

On the other hand, the piping losses are determined from the following equation:

$$
P_{\text {losspip }}=L_{p 1} \Delta \mathrm{T}_{1}-L_{p 2} \Delta \mathrm{T}_{1}^{2}+L_{p 3} \Delta \mathrm{T}_{1}^{3}
$$

Readers interested in the detailed calculation of the collector piping losses are advised to consult references [3-6,23].

Finally, the power of the CSP collector is

$$
P_{\text {collector }}=P_{\text {abs }}-P_{\text {losscol }}-P_{\text {losspip }}
$$

where Equations (3) and (6) define the collector thermal losses $P_{\text {losscol }}$ and piping losses, $P_{\text {losspip }}$, respectively.

The mass flow rate of the basic heat transfer fluid, thermal oil, can be given by the following:

$$
m_{\text {oil }}=\frac{P_{\text {collected }} A_{\text {aperture }}}{C_{p_{\text {oil }}}\left(T_{\text {field }_{\text {outlet }}}-T_{\text {field }_{\text {inlet }}}\right)}
$$

where

$A_{\text {aperture: }}$ is the total aperture $\left(\mathrm{m}^{2}\right)$

$T_{\text {field outlet }}$ and $T_{\text {field inet }}$ are the outlet and inlet temperature of the thermal oil in the solar field.

The Dowtherm fluid was used in this CSP loop since it offers good thermal stability at temperatures up to $625^{\circ} \mathrm{F}\left(330^{\circ} \mathrm{C}\right)$. The maximum recommended film temperature is $675^{\circ} \mathrm{F}\left(360^{\circ} \mathrm{C}\right)$. Between $5500^{\circ} \mathrm{F}$ and $600{ }^{\circ} \mathrm{F}\left(290^{\circ} \mathrm{C}\right.$ and $\left.315^{\circ} \mathrm{C}\right)$, its stability is 15 to 30 times greater than that of a typical hot oil. Where the specific heat of the thermal oil is [37]:

$$
C_{P_{\text {oil }}}=1509+2.496 T_{\text {oil }}+7.887 * 10^{-4} T_{\text {oil }}^{2}
$$

where $T_{\text {oil }}$ is the thermal oil temperature.

The thermal heat accumulated in the thermal storage tank during the charging process is:

$$
Q_{\text {storage tank }}=\eta m_{\text {oil }}\left(T_{5}-T_{6}\right) C_{p_{\text {oil }}}
$$

where $m_{\text {oil }}$ is the oil flow rate obtained from Equation (8) and $C_{\text {poil }}$ is the specific heat of thermal oil in the base fluid.

The thermal heat during discharging process is [31]:

$$
Q_{\text {storage tank }}=m_{\text {oil }}\left(T_{\text {hot tank }}-T_{\text {cold tank }}\right) C_{p_{\text {oil }}}=\eta m_{\text {salt }}\left(T_{\text {hot tank }}-T_{\text {cold tank }}\right) C_{p_{\text {salt }}}
$$

$m_{\text {salt }}:$ mass of salt in the storage thermal tank 
$\eta$ : Efficiency of heat exchanger

The energy balance at the ORC cycle gives the following [23]:

$$
\begin{aligned}
& W_{\text {ORC }}=m_{r e f}\left(h_{1}-h_{2}\right) \\
& Q_{W H B}=m_{r e f}\left(h_{1}-h_{4}\right) \\
& Q_{C O N D}=m_{r e f}\left(h_{2}-h_{3}\right) \\
& W_{P_{\text {ORC }}}=m_{r e f}\left(h_{4}-h_{3}\right)
\end{aligned}
$$

where,

$h_{1}$ : enthalpy at the outlet of the waste heat boiler $(\mathrm{kj} / \mathrm{Kg})$

$h_{2}$ : enthalpy at the exit of the vapor turbine $(\mathrm{kj} / \mathrm{Kg})$

$h_{3}$ : enthalpy at the condenser outlet $(\mathrm{kj} / \mathrm{kg})$

$h_{4}$ : enthalpy at ORC pump outlet $(\mathrm{kj} / \mathrm{kg})$

$m_{\text {ref: }}$ refrigerant mass flow rate $(\mathrm{kg} / \mathrm{s})$

An environmentally sound quaternary refrigerant with low GWP was used in the ORC cycle and its enthalpies and entropies, as well as its thermal properties, were calculated using the REFPROP program [23-27].

The ORC efficiency can be calculated as:

$$
\eta_{\text {ORC }}=\frac{W_{O R C}-W_{P_{O R C}}}{Q_{W H B}}
$$

where

$W_{O R C}$ and $W_{P O R C}$ represent the work produced by the ORC and the work used by the ORC pump.

$Q_{W H B}$ : thermal energy supplied by the waste heat boiler.

$$
\eta_{C S P}=\frac{Q a b s}{Q_{C S P}}
$$

where,

$W_{\text {poil }}:$ work used by the thermal oil pump

$Q_{C S P}$ is the CSP power collected and defined by Equation (1).

Finally, the hybrid system efficiency is:

$$
\eta_{S H}=\frac{W_{O R C}-W_{P_{\text {ORC }}}-W_{P_{\text {oil }}}}{\text { Qcollector }}
$$

where $Q_{\text {collector }}$ represents the collected CSP power and given by Equation (2).

The hybrid system refers to the CSP collector, thermal oil loop and the ORC cycle.

\subsection{Nanofluid Heat Transfer Fluid}

The basic fluid in the CPS loop is the thermal oil. However, nanofluids have been added to the thermal oil to enhance its thermal properties. Sharama et al. [25], Sami [26] and Marefati et al. [31] presented equations to calculate the thermophysical and thermodynamic properties of nanofluids such as specific heat, thermal conductivity, viscosity and density, employing the law of mixtures as a function of the volumetric concentration of nanoparticles;

$$
\alpha_{\text {total }}=\alpha_{\text {particles }}+\alpha_{\text {base fluid }}
$$


where $\alpha$ represents a particular thermophysical property of the nanofluid under investigation.

The nanofluid thermal and thermophysical properties, $\alpha_{\text {total }}$, can be calculated as follows:

$$
\alpha_{\text {total }}=\alpha_{\text {base fluid }}+\alpha_{\text {particles }}(\Phi)
$$

where $\Phi$ represents the nanoparticles volumetric concentration.

The thermal conductivity is related to thermal diffusivity and density of the nanofluids as follows:

$$
\lambda=\alpha \delta C_{p}
$$

where $C p$ is the specific heat, $\alpha$ is the thermal diffusivity, $\lambda$ and $\rho$ represent the thermal conductivity and density, respectively.

The specific heat is calculated for nanofluids as follows $[25,26,31]$ :

$$
c_{p n f}=\frac{(1-\varnothing)(\rho C p)_{b f}+\varnothing(\rho C p)_{p}}{(1-\varnothing) \rho_{b f}+\varnothing \rho_{p}}
$$

where "nf" and "bf" refer to nanofluid and basic fluid, respectively. $\varnothing$ is the nanofluid particle concentration. $\rho$ represents the density.

The density of nanofluids can be written as follows [25,26,31]:

$$
\rho_{n f}=\varnothing_{p} \rho_{p}+(1-\varnothing) \rho_{b f}
$$

$\rho_{p}$ represents the density of the nanoparticle.

\subsection{Numerical Procedure}

The model describing the energy conversion mechanisms taking place during energy conversion in the CSP, thermal oil loop and the ORC cycle was presented in Equations (1)-(23). The logical diagram presented in Figure 3 describes the sequence of steps and calculations of the model in question. The Equations (1)-(23) were integrated in the finite-difference formulations. Iterations were performed using MATLAB iteration techniques until a converged solution is reached with acceptable iteration error as \pm 0.05 . The logical diagram starts inputting solar radiations, nanofluids, specifications and parameters to start the calculation of the CSP collected power, thermal oil flow, storage tank, refrigerant flow and finally the ORC components and work produced. To this end, the CSP, ORC and hybrid system efficiencies were calculated. 


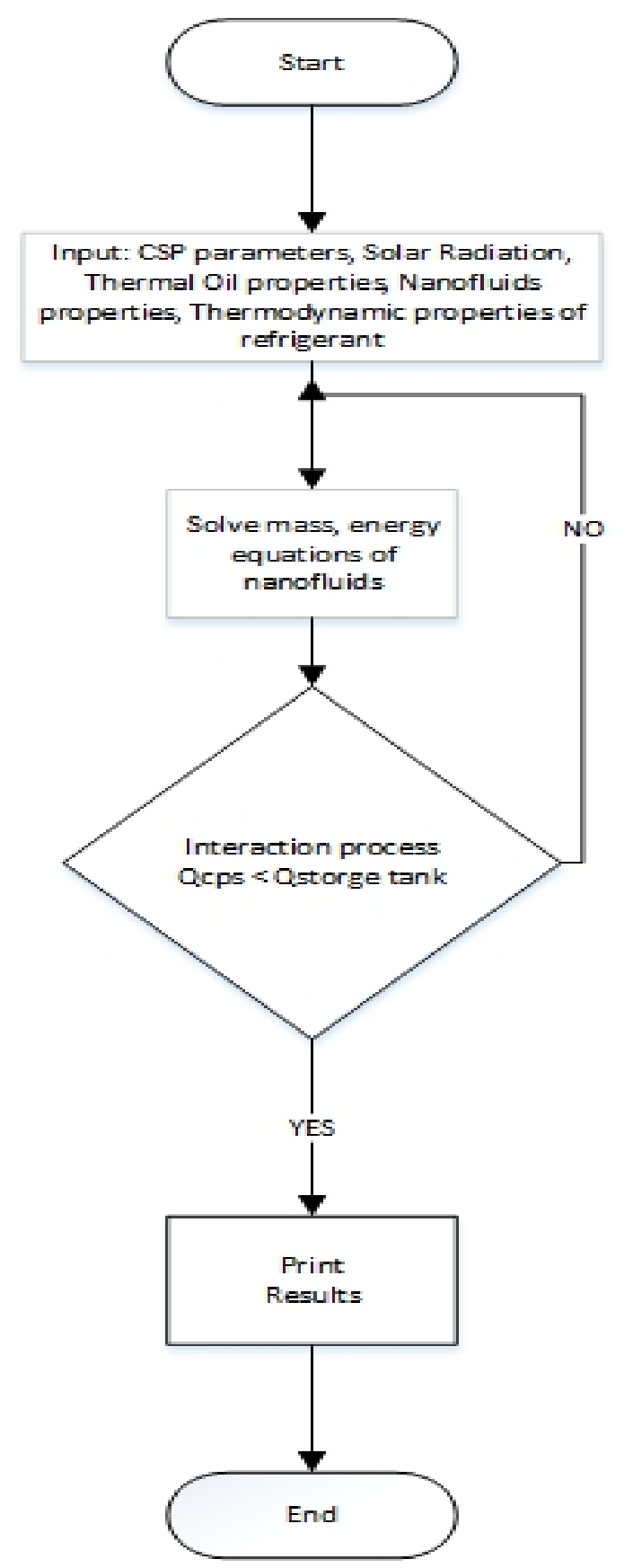

Figure 3. Logical diagram for numerical model.

\section{Discussion and Analysis}

Samples of the predicted results for the CSP, thermal oil loop and ORC cycle are presented under different inlet conditions, and are analyzed and discussed in the following sections for different solar radiations-550, 750, 1000 and $1200 \mathrm{w} / \mathrm{m}^{2}$-and different angles of incidence at 8 a.m., 12 p.m. and 16.00 p.m., and with different nanofluids- $\mathrm{Al}_{2} \mathrm{O}_{3}, \mathrm{CuO}, \mathrm{Fe}_{3} \mathrm{O}_{4}$ and $\mathrm{SiO}_{2}$-with a mainly thermal oil supply with exit temperatures of the CSP collector of $166.5^{\circ} \mathrm{C}\left(331^{\circ} \mathrm{F}\right)$ and $149.5^{\circ} \mathrm{C}\left(301{ }^{\circ} \mathrm{F}\right)$, respectively, and an ambient temperature of $25^{\circ} \mathrm{C}\left(77^{\circ} \mathrm{F}\right)$. Other output temperatures of the CSP solar collector were considered: $182^{\circ} \mathrm{C}\left(361^{\circ} \mathrm{F}\right)$, and $199^{\circ} \mathrm{C}\left(391^{\circ} \mathrm{F}\right)$.

Figures 4-6 present the results of the characteristics of the CSP hybrid system, including absorbed thermal energy, collected thermal energy by the CSP, thermal energy stored, thermal energy delivered to the waste heat boiler of the ORC and finally work produced by ORC, where the thermal oil is the 
base fluid at three different times during the day, and with different angles of incidence of the solar radiation: $17.44^{\circ}$ at $8: 00$ a.m., $77.44^{\circ}$ at $12: 00$ p.m. and $137.44^{\circ}$ at 16:00 p.m. Specifically, Figure 3 displays the power absorbed by the CSP at different times during the day and at different angles of incidence in the month of January 2018. It is apparent that the maximum power absorbed by the CSP occurs at midday-12:00 p.m. However, the highest power was observed at 8:00 a.m. due to the solar radiation being higher at 8:00 a.m. compared to at 4:00 p.m. On the other hand, Figure 4 shows the power produced by the ORC at different times during the day and at different angles of incidence. This figure also confirms that the maximum power produced by the ORC occurs at midday. Furthermore, the main parameters of the CSP system-power absorbed, power collected, storage tank thermal energy and work generated by the ORC at different direct normal insolation and angles of incidence-are depicted in Figures 3 and 4. Solar radiations depicted in Figure 4 were measured at the site using a Hobo environmental station. It is quite evident from the results displayed in these figures that the higher the solar radiation, the higher the characteristics of the CSP system and the power produced by the ORC with the use of thermal oil as base fluid. In addition, the solar radiation intensities corresponding to the different angle of incidences are shown in Figure 3. Figure 4 demonstrates that the higher the solar radiation, the higher the efficiencies of CPS and hybrid systems. Furthermore, the results displayed in this figure also demonstrate the maximum efficiencies of the CSP and the hybrid system occur at mid-dia. This can be attributed to the fact that higher solar radiation at higher angles of incidence increases the thermal energy absorbed by the CPS collector and the thermal energy delivered to the waste heat boiler of the ORC.

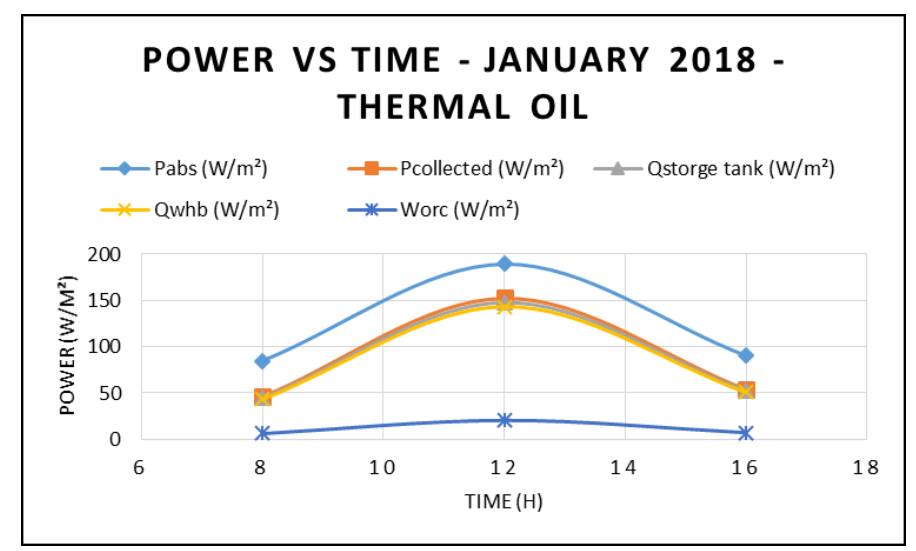

Figure 4. CSP hybrid system results with thermal oil as base fluid.

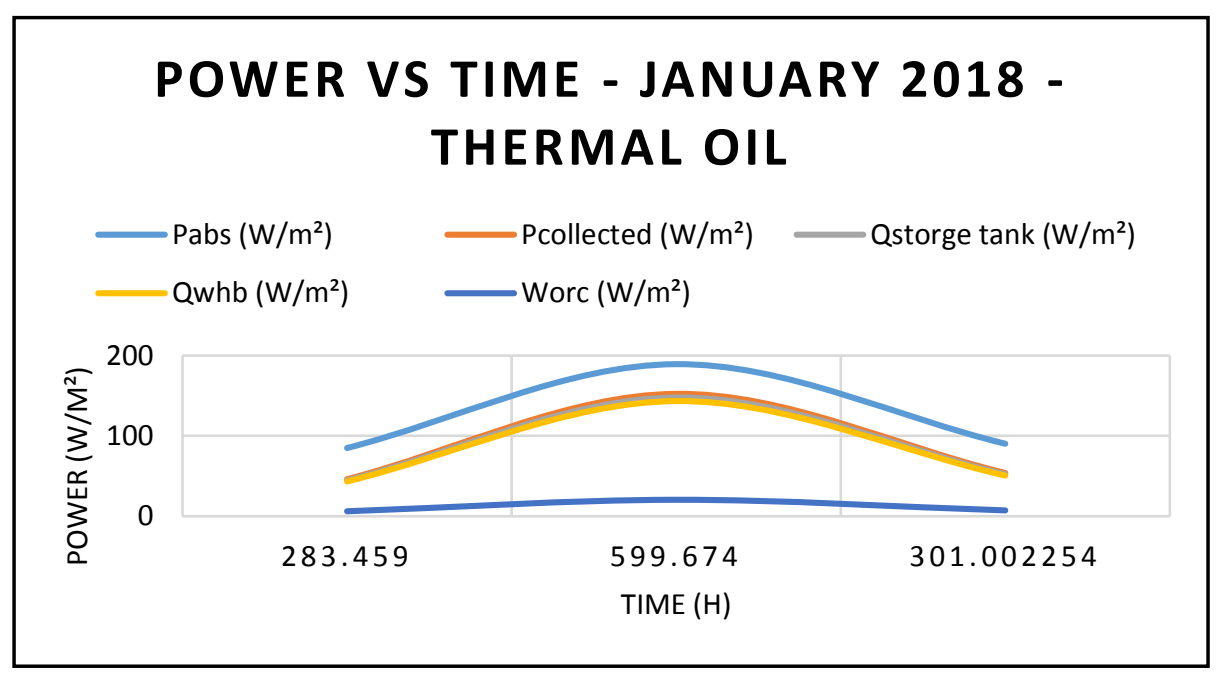

Figure 5. CSP hybrid system results with thermal oil as base fluid. 


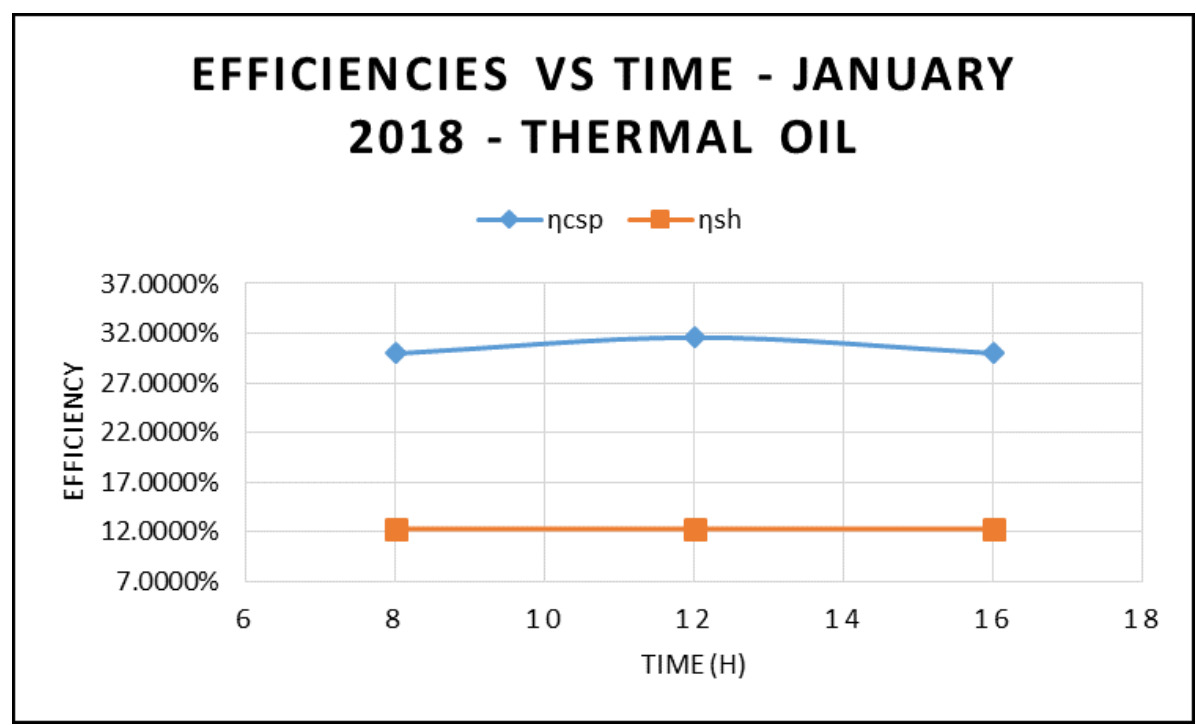

Figure 6. Efficiency of CSP collector and hybrid system at different angle of incidence and thermal oil as base fluid.

This, in turn, increases the ORC work produced and the efficiencies of the CPS and the hybrid system as shown in Figure 5, where the efficiency of CSP collector and hybrid system are plotted against different angle of incidence and thermal oil as base fluid. The results in this figure also clearly demonstrate that the maximum efficiencies occur at 12:00 and solar radiation of $599.67 \mathrm{w} / \mathrm{m}^{2}$.

$\mathrm{Al}_{2} \mathrm{O}_{3}$ is one of the most studied nanofluid in the literature $[17,26,29,30]$; in the following sections, we present first samples of the results in Figures $7-11$ for $5 \%$ and $20 \%$ concentrations of nanofluid $\mathrm{Al}_{2} \mathrm{O}_{3}$. This is followed by a discussion and analysis of the impact of the nanofluid concentration ranging from $1 \%$ to $50 \%$ of $\mathrm{Al}_{2} \mathrm{O}_{3}$ in Figures 12-17 on the different characteristics of the CSP collector, such as: thermal energy absorbed by solar collector, thermal energy collected, thermal energy in storage tank, thermal energy supplied to the waste heat boiler of ORC, work produced at the ORC's turbine, and efficiencies of the CSP collector and the CSP hybrid system. On the other hand, Figure 5 compares the efficiency of the CSP collector and the efficiency of the hybrid system calculated on the basis of Equations (17) and (18), respectively.

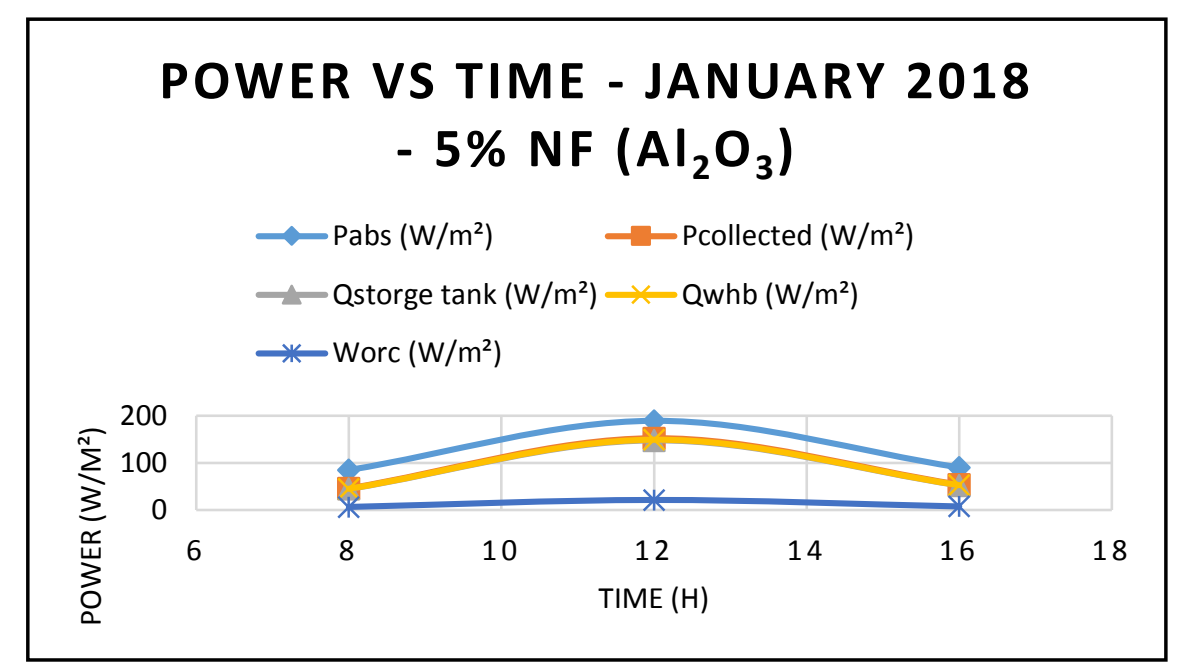

Figure 7. Characteristics of the CSP collector and hybrid system at concentration of $5 \% \mathrm{of}_{2} \mathrm{O}_{3}$. 


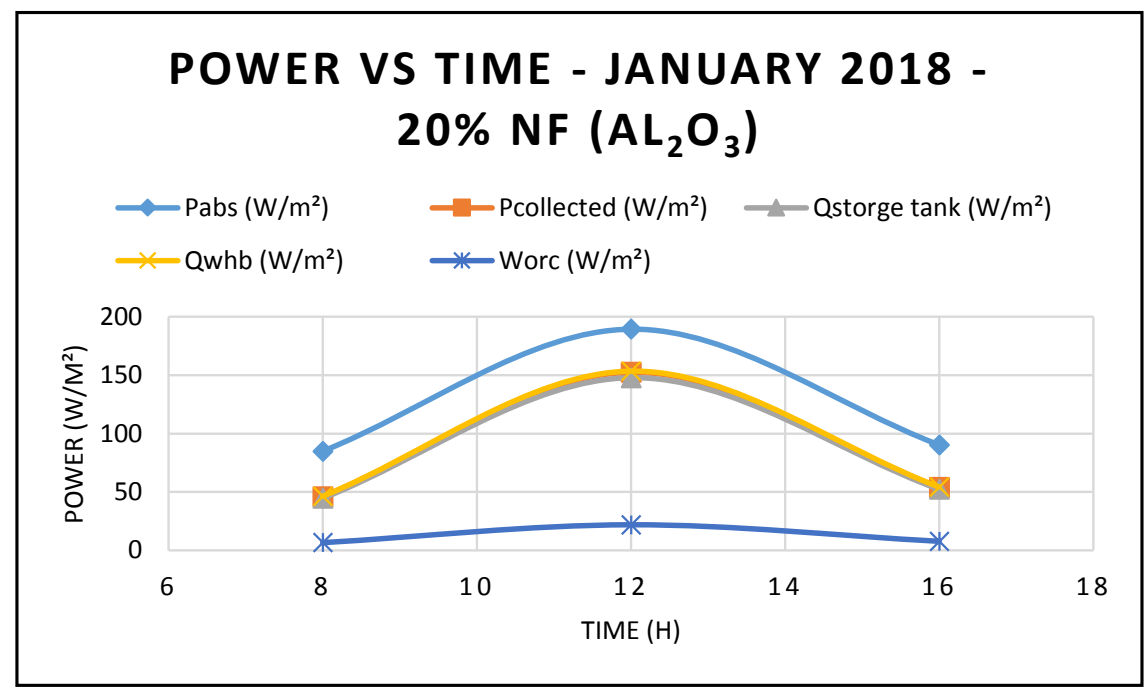

Figure 8. Characteristics of the CSP collector and hybrid system at concentration of $20 \%$ of $\mathrm{Al}_{2} \mathrm{O}_{3}$.

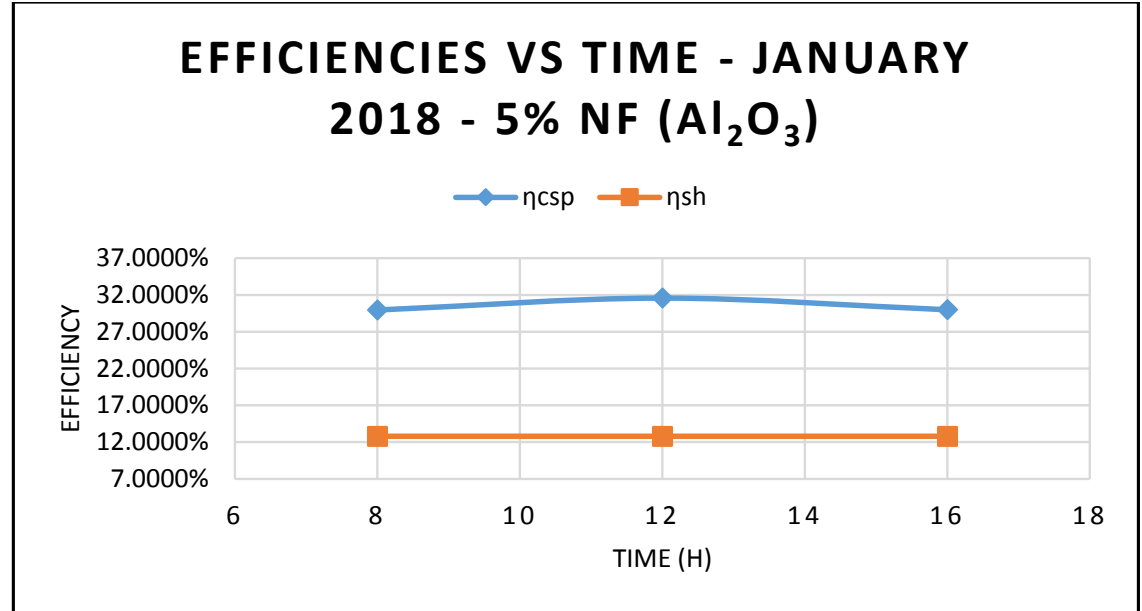

Figure 9. Efficiencies of the CSP collector and hybrid system at a concentration of $5 \% \mathrm{Al}_{2} \mathrm{O}_{3}$.

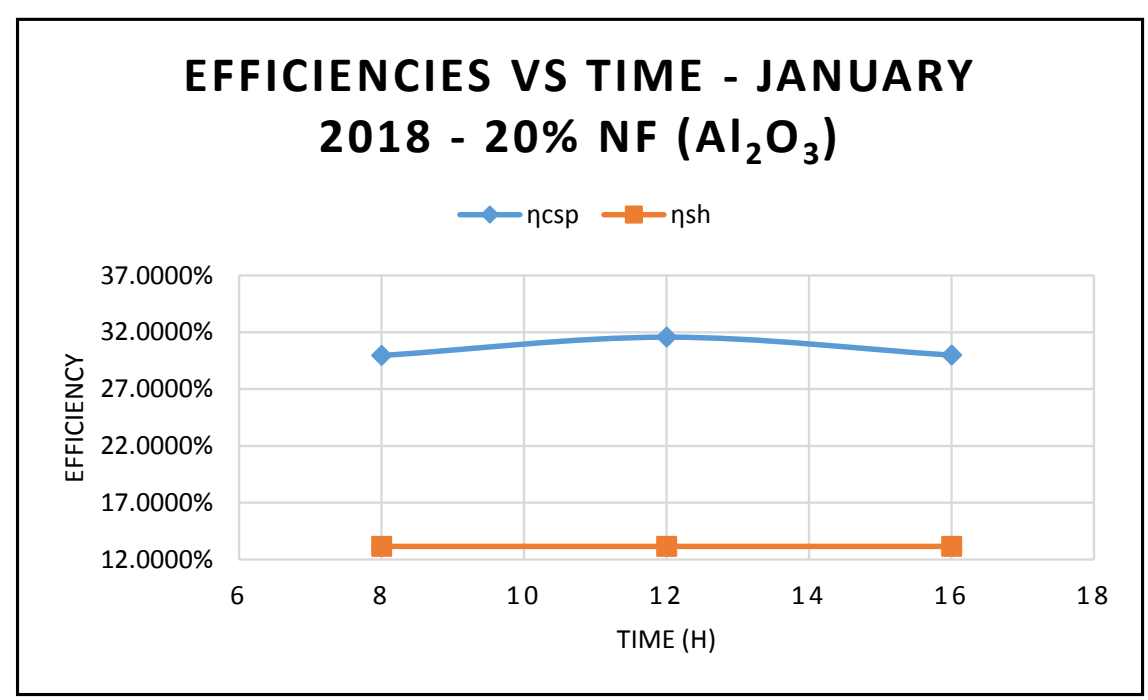

Figure 10. Efficiencies of the CSP collector and hybrid system at a concentration of $20 \% \mathrm{Al}_{2} \mathrm{O}_{3}$. 


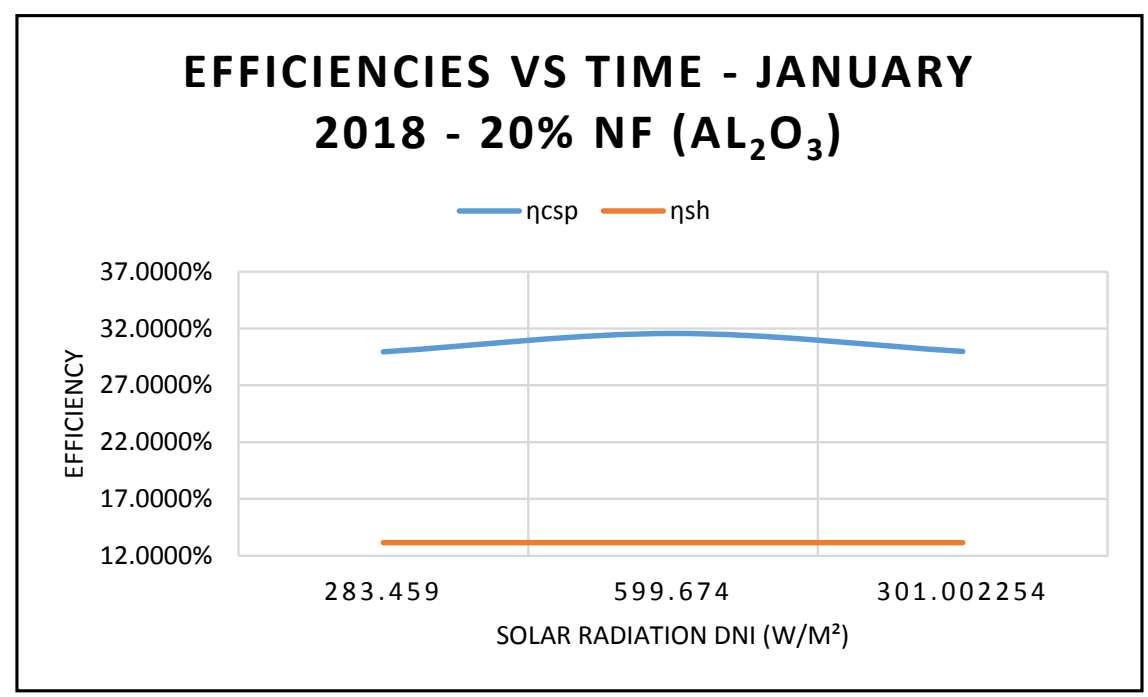

Figure 11. Efficiencies of the CSP collector and hybrid system at different radiations and a concentration of $20 \% \mathrm{Al}_{2} \mathrm{O}_{3}$.

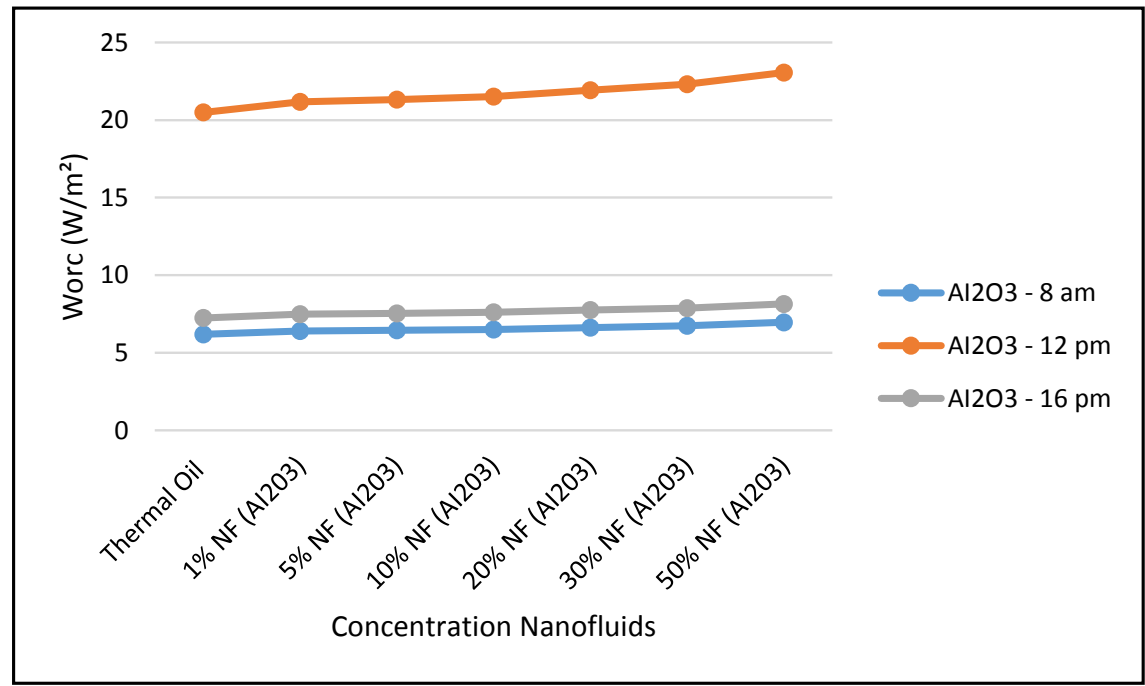

Figure 12. Work produced by ORC at different concentrations of $\mathrm{Al}_{2} \mathrm{O}_{3}$.

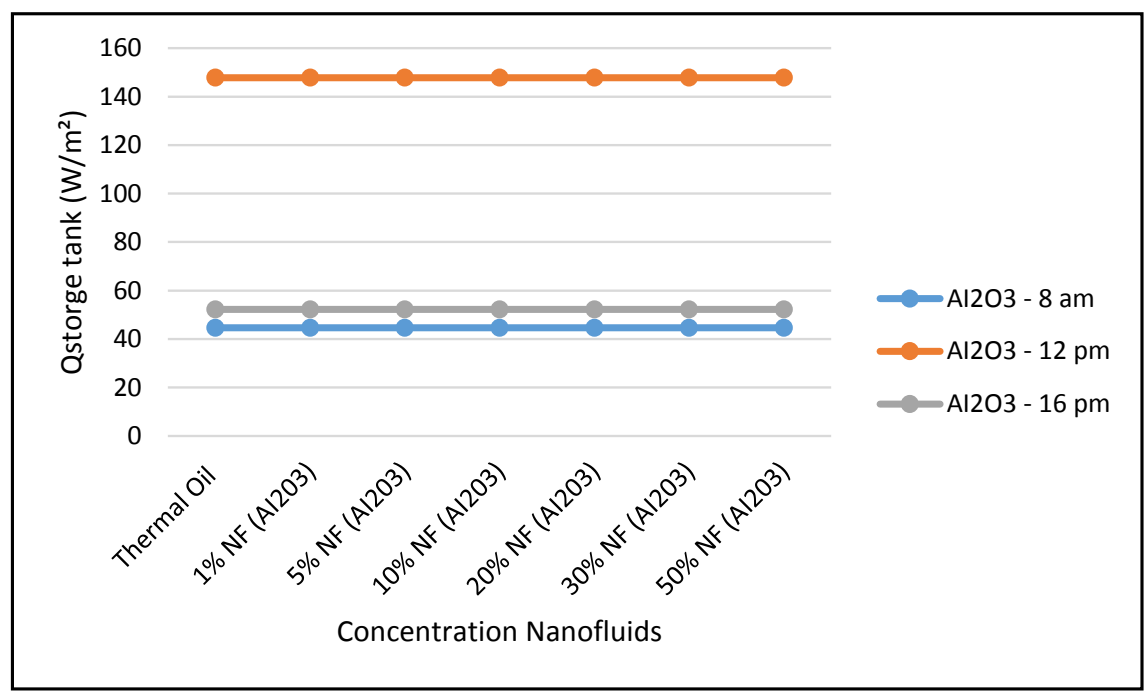

Figure 13. Thermal energy storage at different concentrations of $\mathrm{Al}_{2} \mathrm{O}_{3}$. 


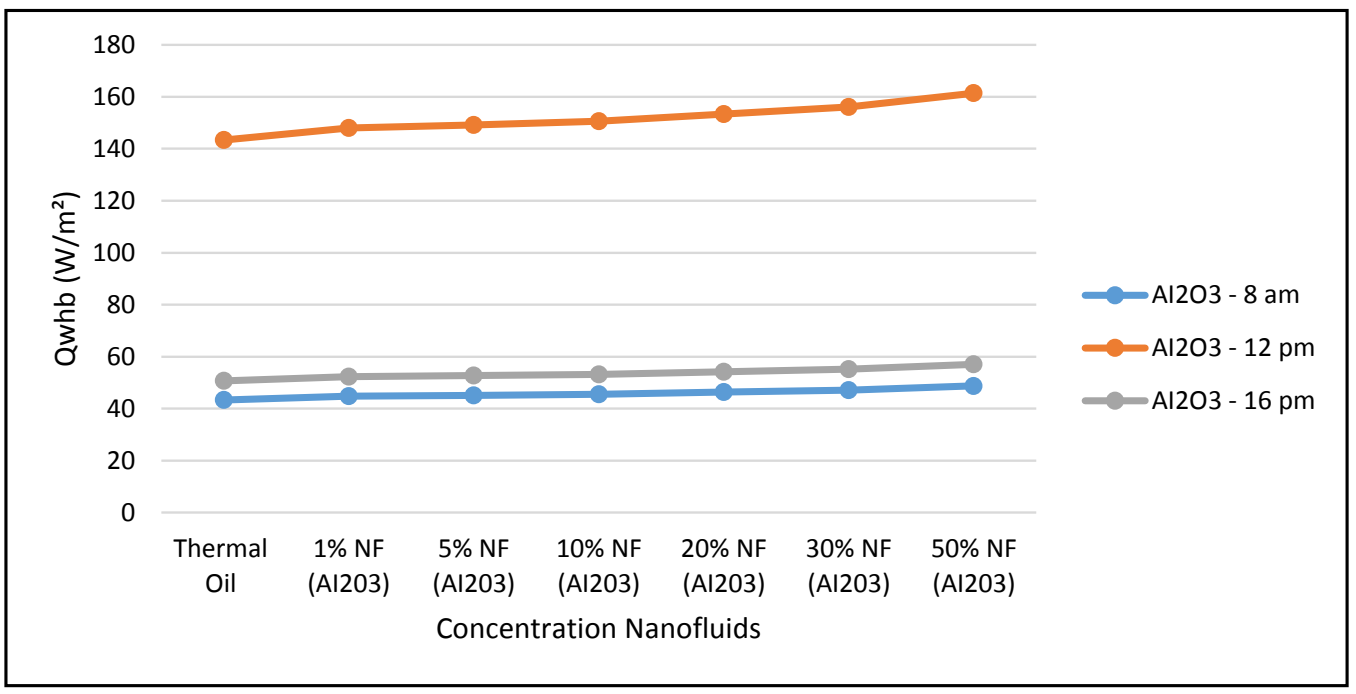

Figure 14. Thermal energy supplied to waste heat boiler storage at different concentrations of $\mathrm{Al}_{2} \mathrm{O}_{3}$.

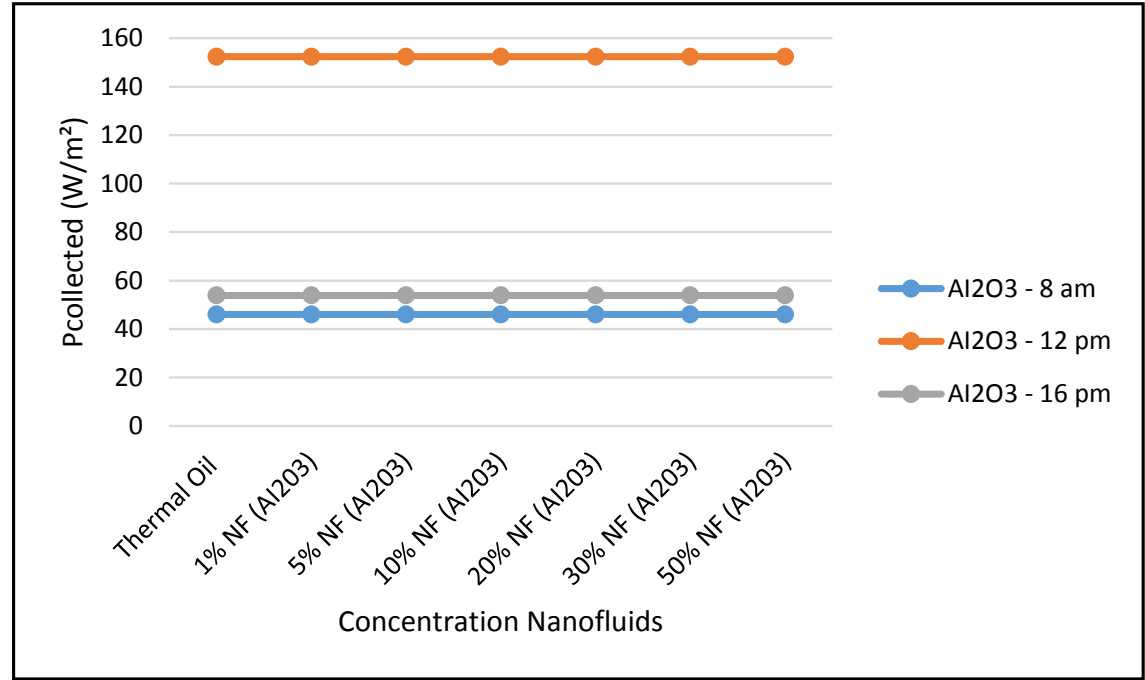

Figure 15. Power collected at CSP at different concentrations of $\mathrm{Al}_{2} \mathrm{O}_{3}$.

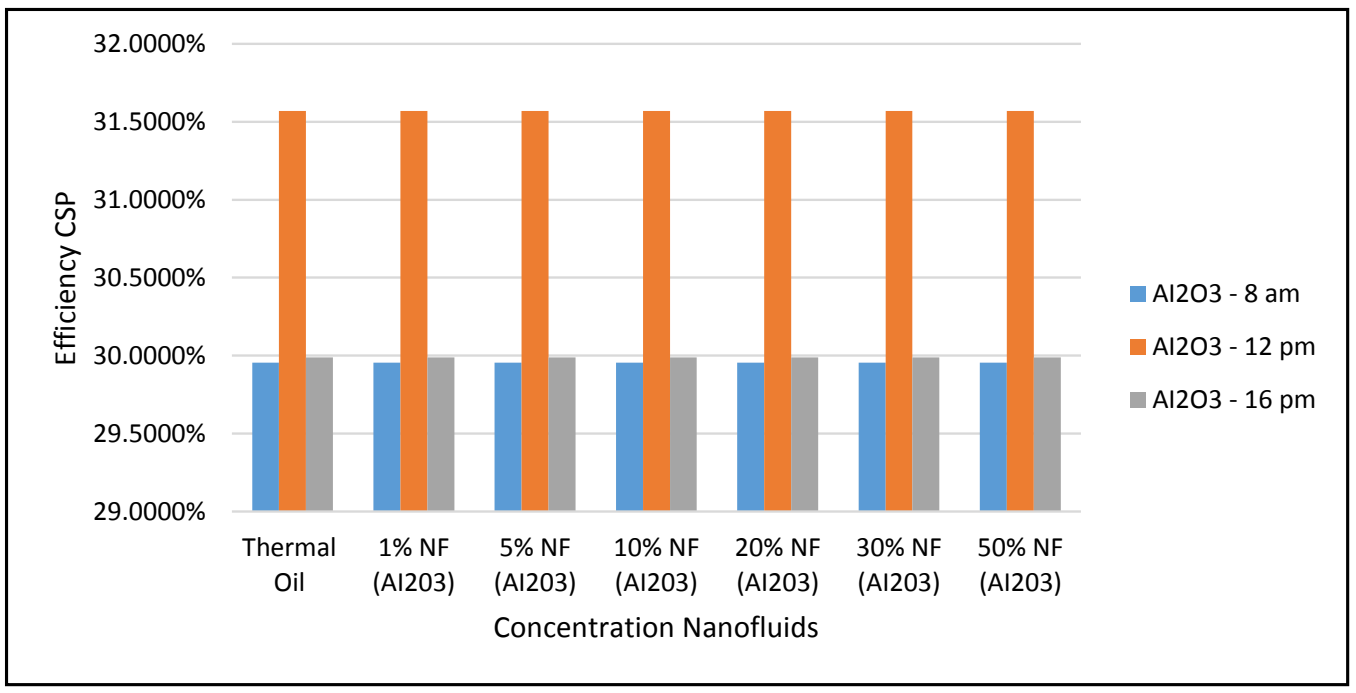

Figure 16. Efficiencies of the CSP collector at different concentrations of $\mathrm{Al}_{2} \mathrm{O}_{3}$. 


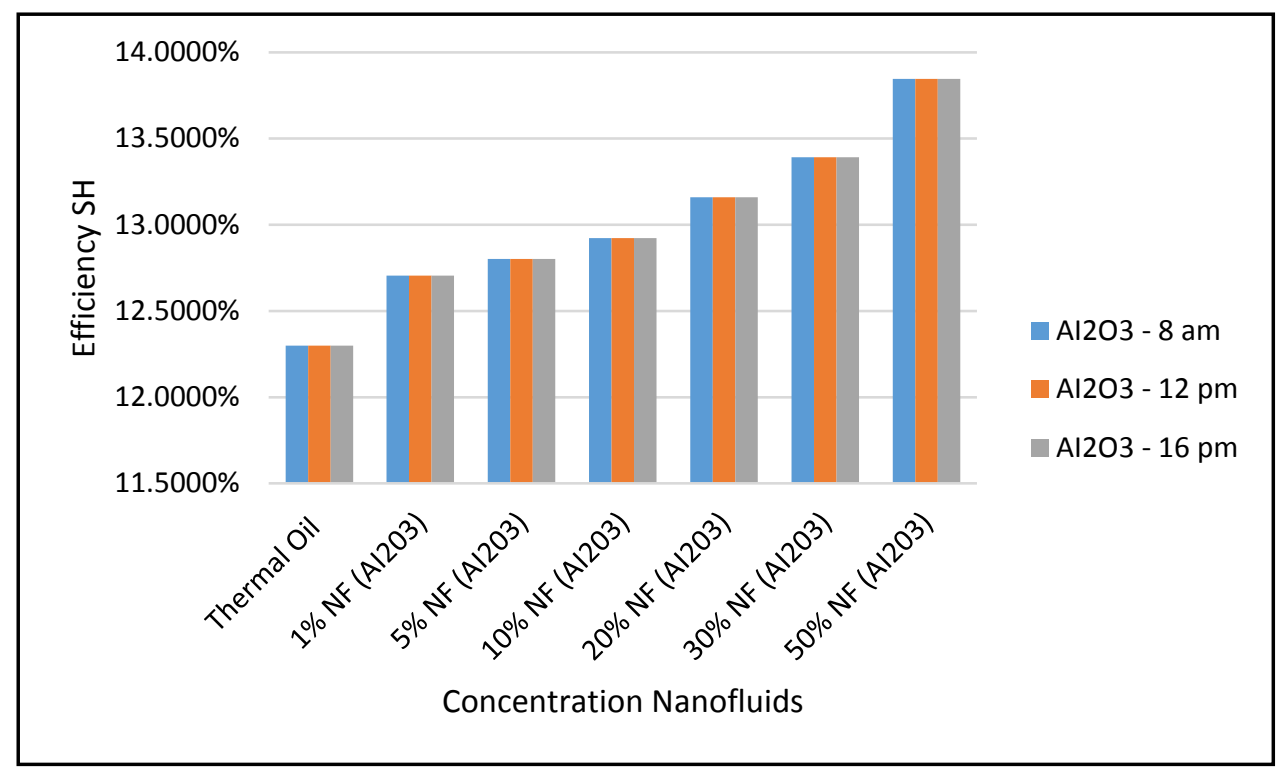

Figure 17. Efficiencies of the CSP hybrid system at different concentrations of $\mathrm{Al}_{2} \mathrm{O}_{3}$.

As expected, the data displayed in this figure show that those efficiencies are maximized at 12:00 p.m., with solar radiation of $599.674 \mathrm{w} / \mathrm{m}^{2}$, as shown in Figure 10.

Furthermore, the predicted results of the CSP system Characteristics using nanofluid $\mathrm{Al}_{2} \mathrm{O}_{3}$ are displayed in Figures 9-11. Nanofluid concentrations of 5\% and 20\% respectively showed that the CSP system characteristics including efficiencies are enhanced with the higher concentrations of nanofluid $\mathrm{Al}_{2} \mathrm{O}_{3}$ over the thermal oil as base fluid presented in Figure 5 and are maximized at midday, when solar radiation is at its highest peak. Also, the depicted results of the efficiencies of the CSP and the hybrid system showed clearly that the CSP efficiency is higher than the hybrid system efficiency and peaked at the midday.

Furthermore, Figures 12-15 demonstrate that the higher the concentration of the nanofluid $\mathrm{Al}_{2} \mathrm{O}_{3}$, the higher the CSP system characteristics, such as ORC performance, thermal energy at the storage tank, and thermal energy supplied to the waste heat boiler of the ORC. Also, the maximum value was achieved by midday, at which point solar radiation is at its highest, at $599.67 \mathrm{w} / \mathrm{m}^{2}$ measured at the site. However, Figure 14 shows that the CSP power collected and calculated by Equation (7) is not significantly influenced by the nanofluid concentrations, since Equation (7) is highly dependent on the thermal and piping losses given by Equations (3)-(6). Figures 16 and 17 display the efficiencies of the CSP collector and the CSP hybrid system, respectively, at different nanofluid concentrations. As expected, the results in these figures clearly indicate that the higher efficiencies of the hybrid system the higher the solar radiations, but, the CSP collector efficiencies are independent of the nanofluid concentrations, as per Equation (17).

Figure 18 depicts the variation of the refrigerant mass flow rate of the ORC cycle at three different times during the day, and different angles of incidence of the solar radiation: $17.44^{\circ}$ at $8: 00$ a.m., $77.44^{\circ}$ at 12:00 p.m. and $137.44^{\circ}$ at 16:00 p.m. The data displayed in this figure clearly demonstrated that the refrigerant flow is maximized at midday, which reflects on the work produced at the ORC vapor turbine, where its maximum value also occurs at same time.

Furthermore, simulated results of characteristics of the CSP collector system under solar radiations of 500, 750, 1000, and $1200 \mathrm{w} / \mathrm{m}^{2}$ occurring at different times of day and different angles of incidence of the solar radiation; $17.44^{\circ}$ at 8:00 a.m., $77.44^{\circ}$ at $12: 00$ p.m. and $137.44^{\circ}$ at $16: 00$ p.m. have been conducted. The purpose of this exercise is to predict the impact of a wide range solar radiations other than those in the previous figures on the characteristics of the CSP collector system. Figure 19 and Figure 24 present these characteristics at midday. As anticipated, the results displayed in these figures show that higher concentration of the nanofluid $\mathrm{Al}_{2} \mathrm{O}_{3}$ enhance the different key parameters 
of the characteristics of the CSP collector such and power absorbed and collected, thermal storage energy, the output work at the ORC, over thermal oil as base fluid. It is noticeable from the results that the ORC key parameters, such as waste heat boiler thermal energy and work produced (cf. Figures 22 and 23), are enhanced with the increase of the solar radiation and the nanofluid concentrations. However, the CSP power absorbed and storage tank thermal energy are only enhanced with the solar radiation. However, it is worthwhile pointing out that nanofluid concentration higher than $20 \%$ could result in higher pressure head losses and pumping power losses in the thermal oil loop and that is undesirable. Therefore, it is important for the designer of such systems to exercise caution when using the $\mathrm{Al}_{2} \mathrm{O}_{3}$ nanofluid $[25,26,30]$. The data presented in Figures 19-21 illustrate that the power absorbed, and power collected by the CSP collector and thermal energy stored in the storage tank are enhanced with the increase of the solar radiation; however, they are independent from the nanofluid $\mathrm{Al}_{2} \mathrm{O}_{3}$ concentrations and thermophysical properties. This can be interpreted in light of Equations (1)-(6). Figures 22 and 23 illustrate that the key parameters of the ORC are waste heat boiler thermal energy supplied to ORC, and the work produced by the vapor turbine of the ORC. The data is as follows.

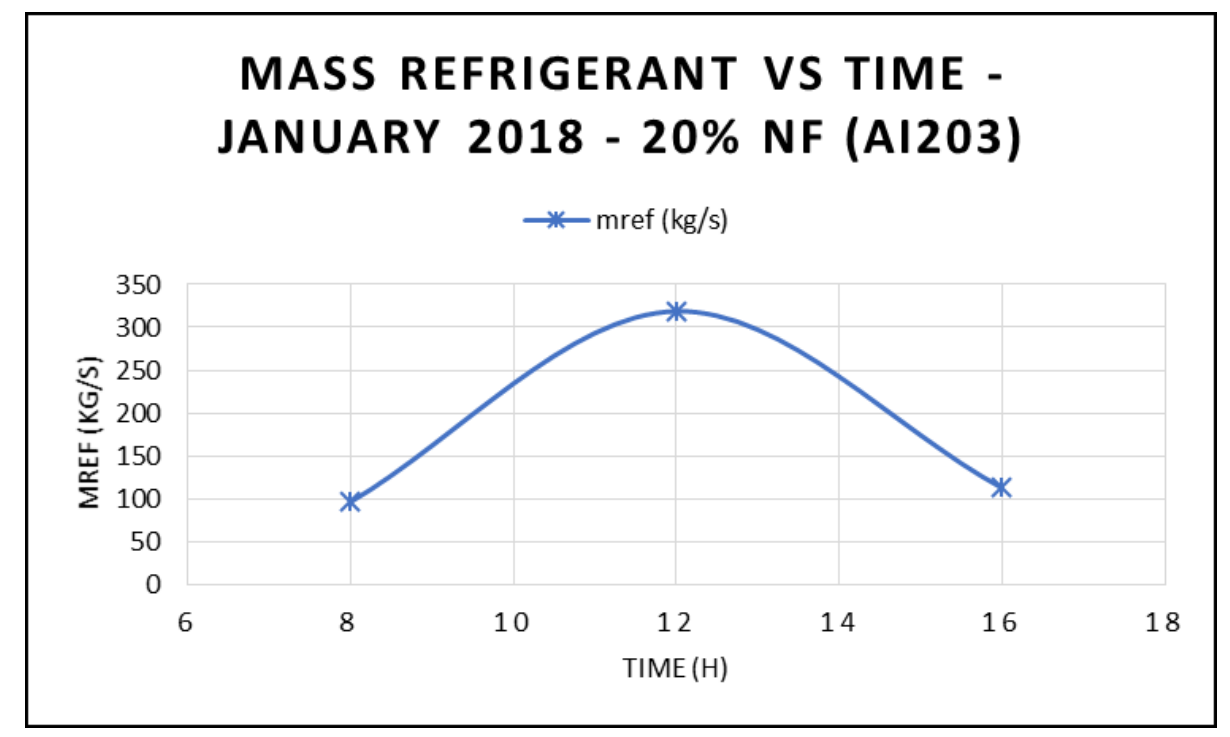

Figure 18. ORC refrigerant flow rate at $20 \%$ concentration of $\mathrm{Al}_{2} \mathrm{O}_{3}$ at different times.

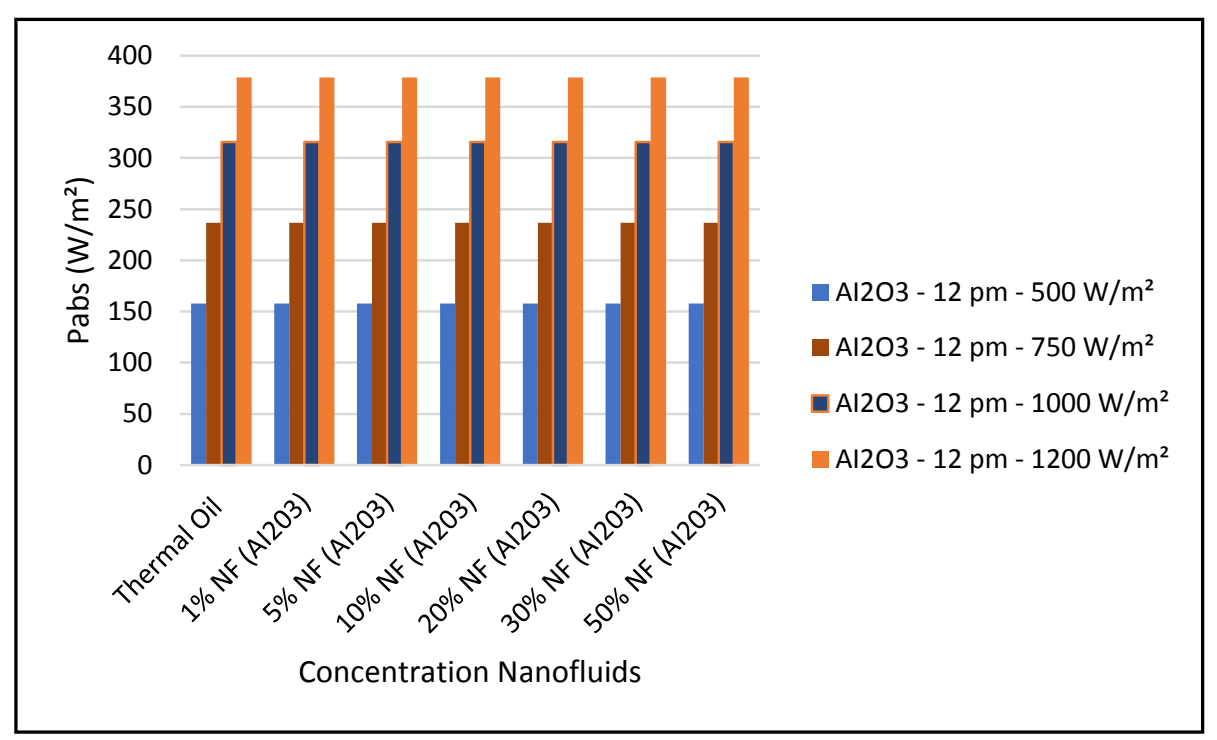

Figure 19. Power absorbed by CSP collector at different concentrations of $\mathrm{Al}_{2} \mathrm{O}_{3}$. 


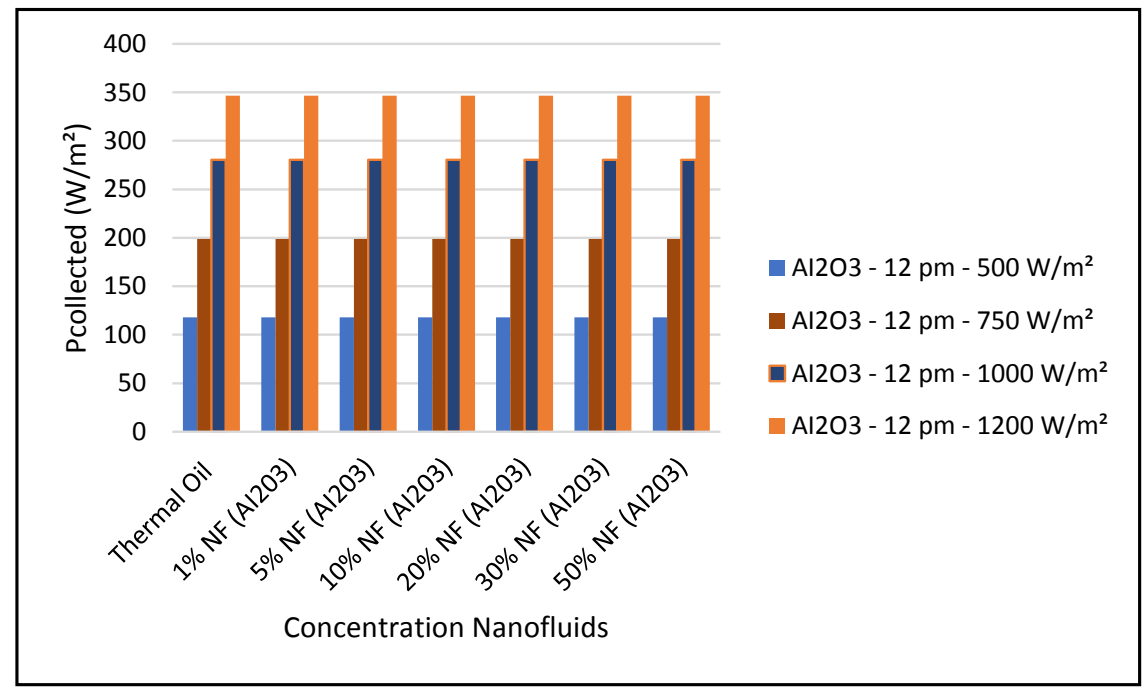

Figure 20. CSP collector power collected at different concentrations of $\mathrm{Al}_{2} \mathrm{O}_{3}$ and solar radiations.

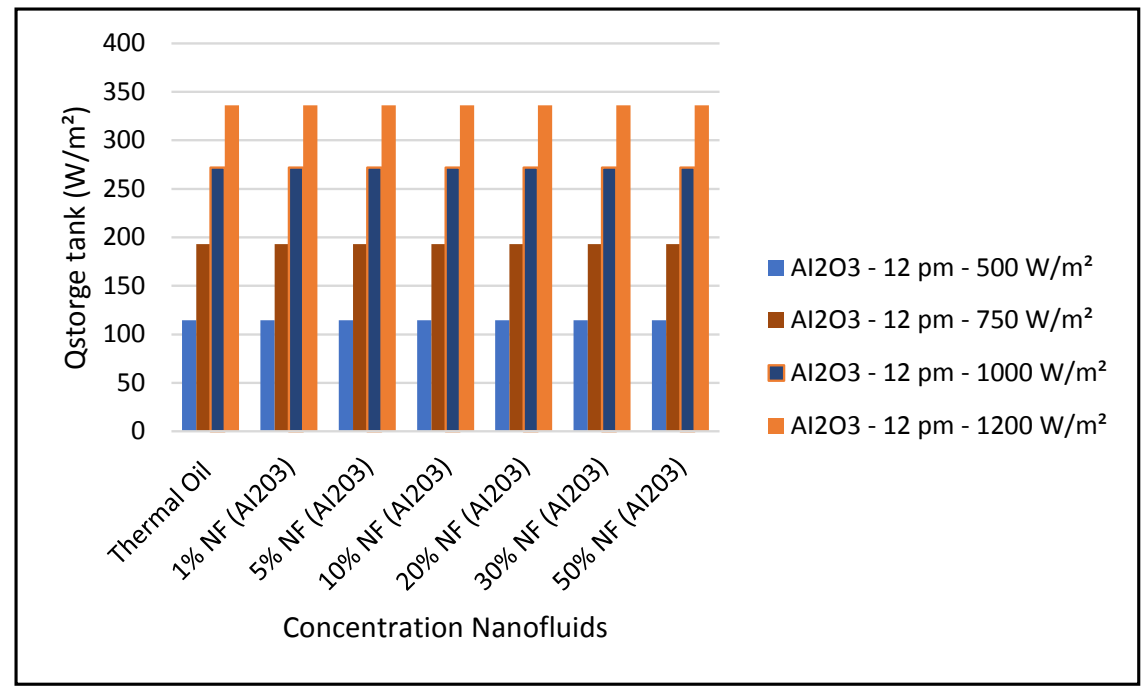

Figure 21. Thermal energy stored in thermal tank at different concentrations of $\mathrm{Al}_{2} \mathrm{O}_{3}$.

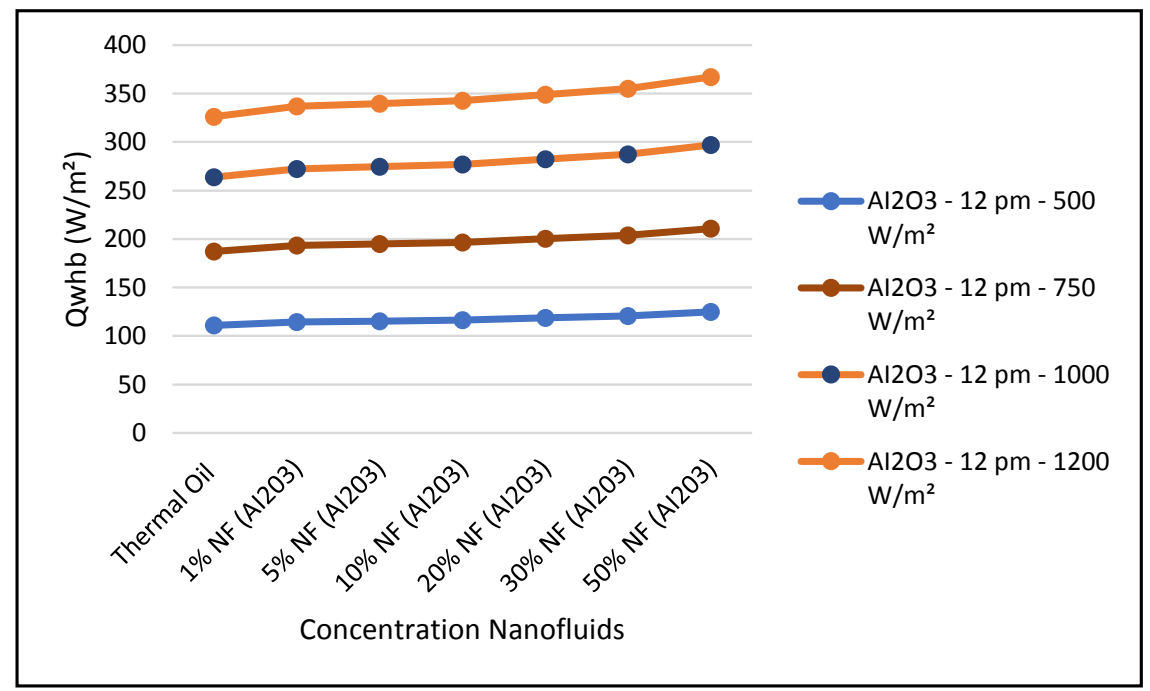

Figure 22. ORC waste heat boiler thermal energy at different concentrations of $\mathrm{Al}_{2} \mathrm{O}_{3}$. 


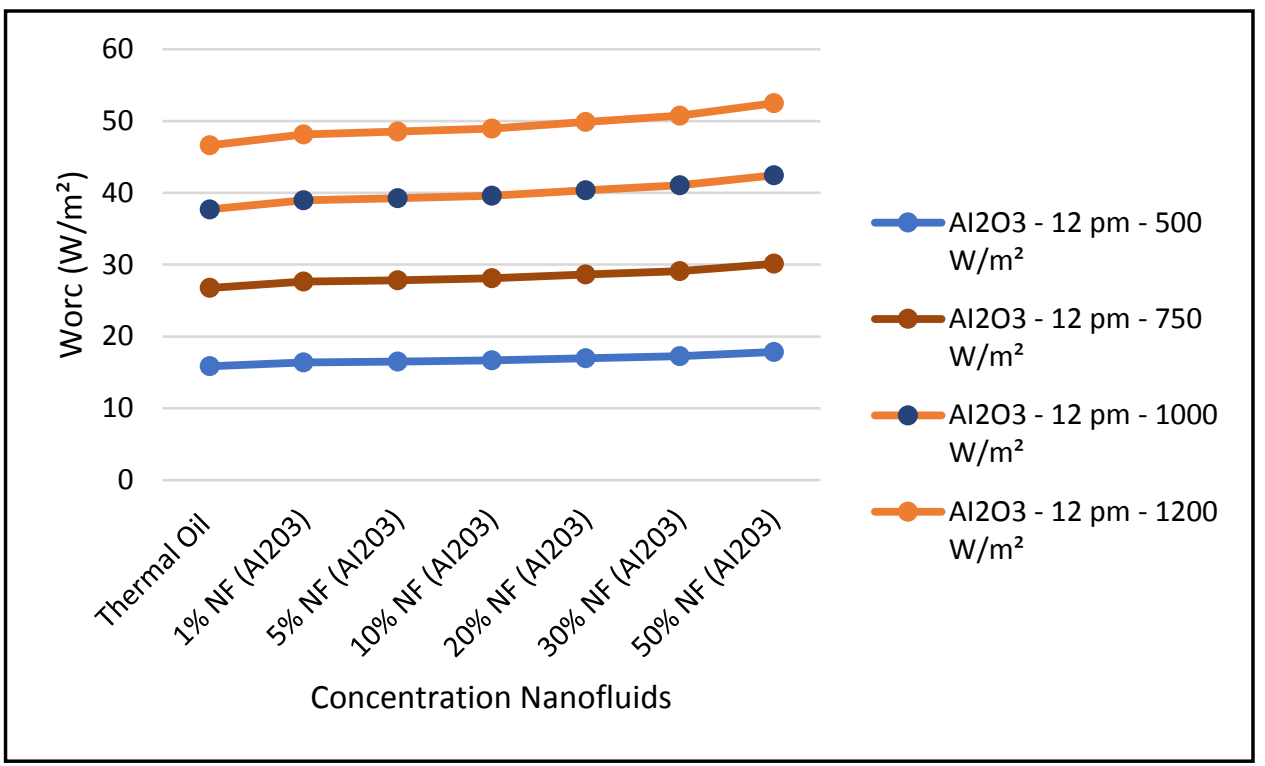

Figure 23. ORC work produced at different concentrations of $\mathrm{Al}_{2} \mathrm{O}_{3}$ and solar radiations.

The figures clearly demonstrate that these key parameters are enhanced by solar radiation and the nanofluid concentrations. Also, in Figure 24, the CSP system hybrid efficiency is plotted at different concentrations of $\mathrm{Al}_{2} \mathrm{O}_{3}$ and solar radiations, showing that hybrid system efficiency was mainly enhanced by the increase of the solar radiation and at higher nanofluid $\mathrm{Al}_{2} \mathrm{O}_{3}$ concentrations over the thermal oil as base fluid. As expected, the maximum efficiency was observed at a solar radiation of $1200 \mathrm{w} / \mathrm{m}^{2}$.

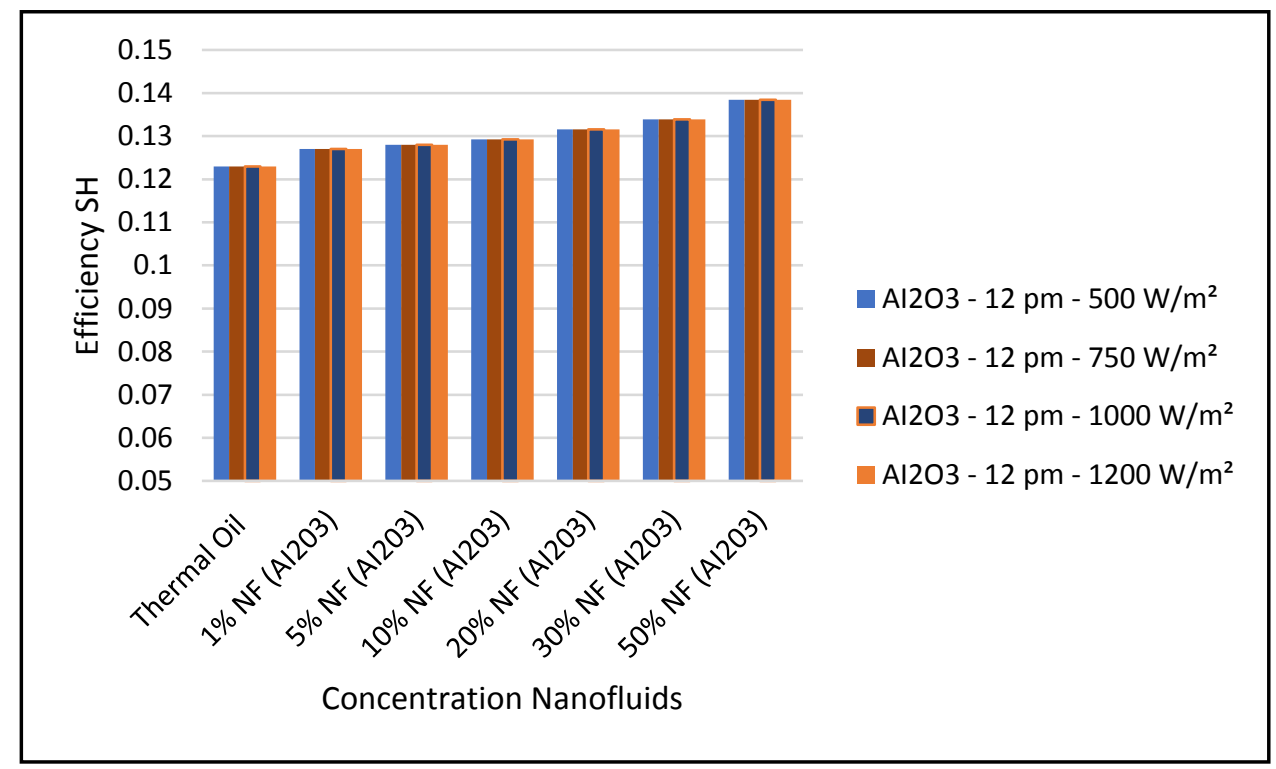

Figure 24. CSP system hybrid efficiency at different concentrations of $\mathrm{Al}_{2} \mathrm{O}_{3}$ and solar radiations.

Other nanofluids, such as $\mathrm{CuO}, \mathrm{Fe}_{3} \mathrm{O}_{4}$ and $\mathrm{SiO}_{2}$, have received significant attention in the literature, namely, $[25,26,30]$. In the following section, we will discuss the impact of using these nanofluids as heat transfer fluid in the thermal oil loop of the CSP solar collector on the characteristics of the CSP hybrid system; Figures 25-28. It evident from the results depicted in these figures that the nanofluid $\mathrm{CuO}$ has the highest characteristic performance among the other nanofluids in the CSP solar collector system over the thermal oil as base heat transfer fluid. This can obviously be attributed to the 
higher thermodynamic and thermophysical and heat transfer properties of the nanofluid $\mathrm{CuO}$ which contribute to outperform other nanofluids over the base fluid thermal oil.

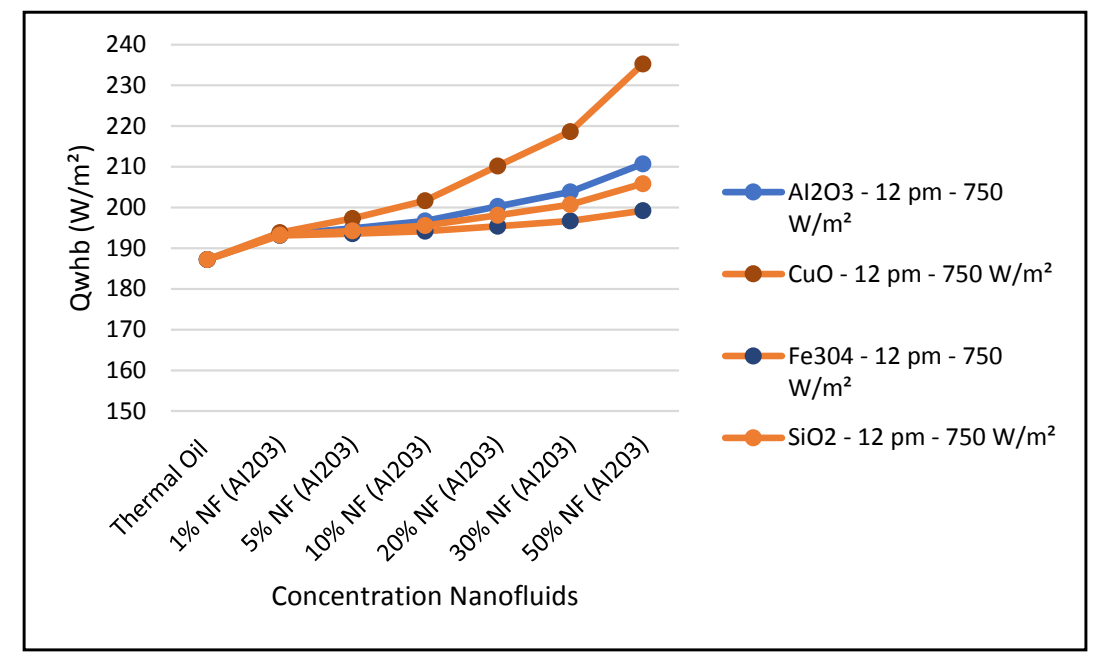

Figure 25. CSP system hybrid ORC waste heat boiler with different nanofluids at different concentrations.

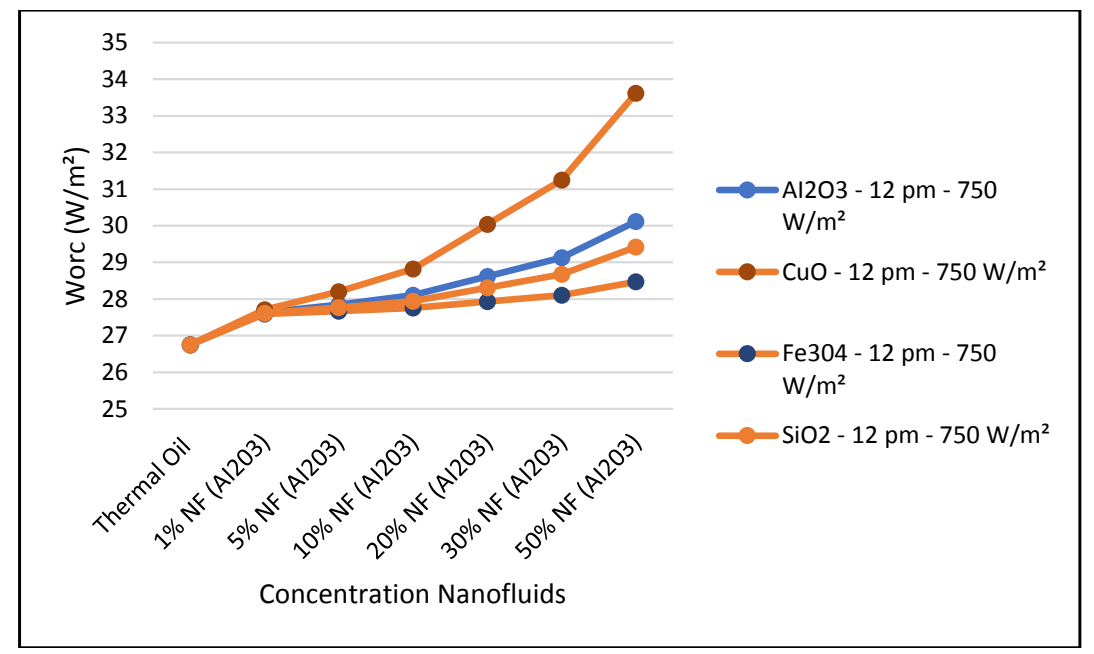

Figure 26. CSP system hybrid ORC work produced with different nanofluids at different concentrations.

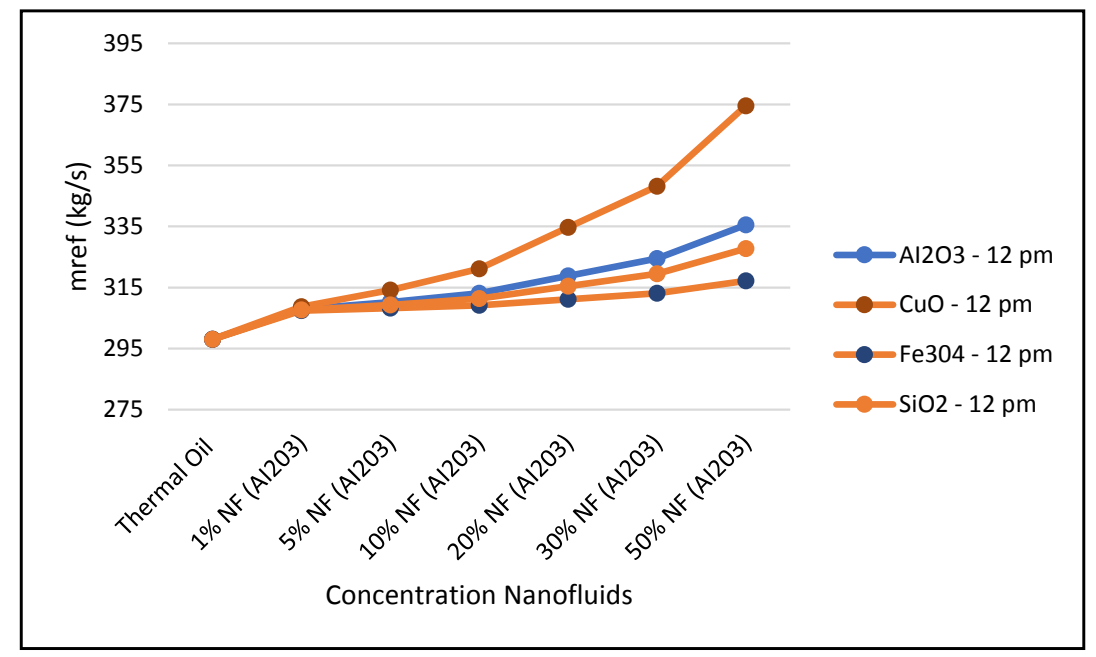

Figure 27. CSP system hybrid ORC refrigerant mass flow rate with different nanofluids at different concentrations. 


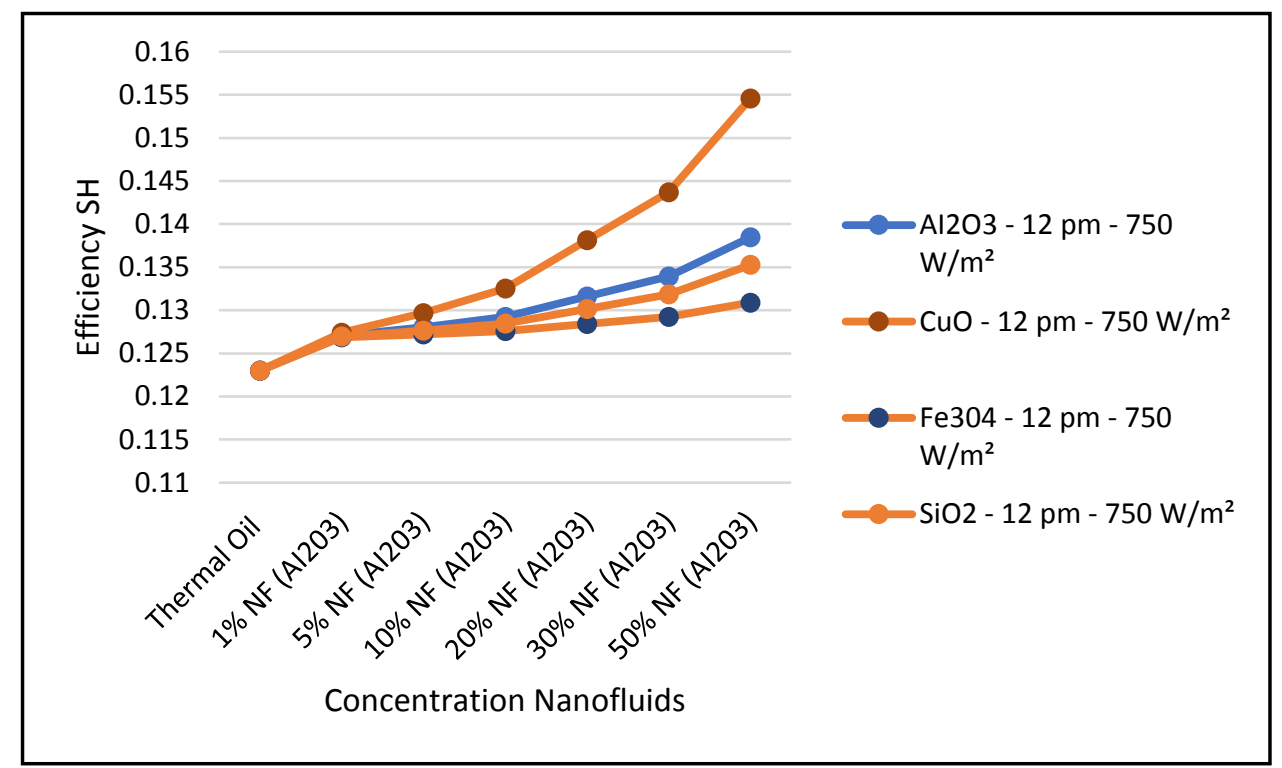

Figure 28. CSP system hybrid efficiency with different nanofluids at different concentrations.

In particular, Figure 26 clearly shows that the nanofluid $\mathrm{CuO}$ has the highest ORC work produced among the other nanofluids under investigation. This results in enhancing the hybrid CSP solar collector system efficiency compared to the other nanofluids under study. It can also be concluded from the results presented in these figures that, in general, the higher the nanofluid concentration, the higher the hybrid system performance characteristics.

One of the significant parameters for demonstrating the enhancement of the CSP solar collector system is the ORC refrigerant mass flow rate, since this parameter impact the work produced by the ORC and the hybrid system efficiency. Figures 27 and 28 show the impact of the various nanofluids considered in this study on the aforementioned parameters. It appears that the higher the concentrations of nanofluids and the higher the solar radiation, the higher the refrigerant mass flow rate and ORC work produced and consequently the CSP hybrid system efficiency. Furthermore, Figures 25-28 also indicate that the nanofluid $\mathrm{CuO}$ outperforms other nanofluids $\mathrm{Al}_{2} \mathrm{O}_{3}, \mathrm{Fe}_{3} \mathrm{O}_{4}$ and $\mathrm{SiO}_{2}$ and has the highest CSP solar collector performance compared to the other nanofluids and thermal oil base fluid under study.

Therefore, Figures 29-31 were constructed to illustrate the impact of the concentrations of nanofluid $\mathrm{CuO}$ in the performance of the ORC system and the CSP hybrid system under different solar radiations at midday: 500,750, 1000 and $1200 \mathrm{~W} / \mathrm{m}^{2}$. As can be seen in Figure 29, the thermal energy supplied by the CSP collector to the ORC loop was enhanced with higher concentrations of this nanofluid at constant solar radiation; and consequently, the ORC work produced was also increased at higher concentrations. It is found that the thermodynamic efficiencies with $\mathrm{CuO}$ nanofluid, under optimum conditions, are higher than those obtained from the base fluid. Also, the results displayed in this figure show that the higher the solar radiation the higher the ORC output. On the other hand, Figure 31 shows that efficiency of the CSP solar collector hybrid system is increased with the increase of the solar radiation and as discussed earlier and is independent of the nanofluid concentrations as per Equation (18). Finally, our results conclude that the combination of the ORC with the $\mathrm{CuO}$ nanofluid is the optimum choice for the CSP solar hybrid system, which is in agreement with what has been reported in the literature, namely, [31,35]. 


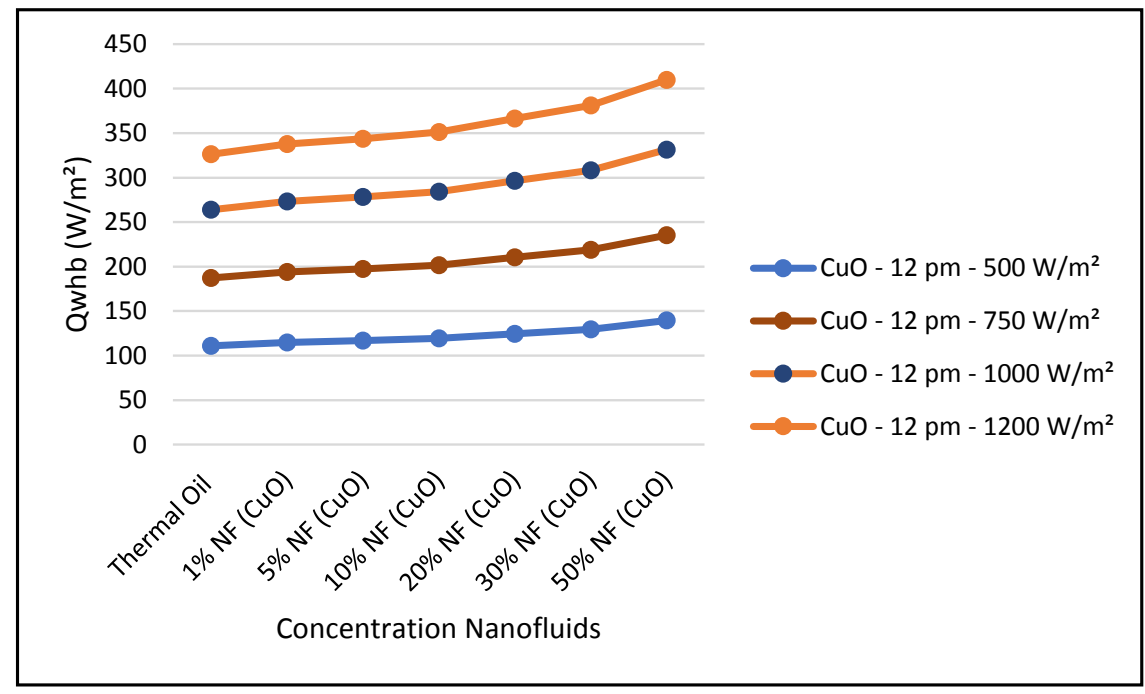

Figure 29. CSP system hybrid waste heat boiler thermal energy at $\mathrm{CuO}$ nanofluid and different concentrations.

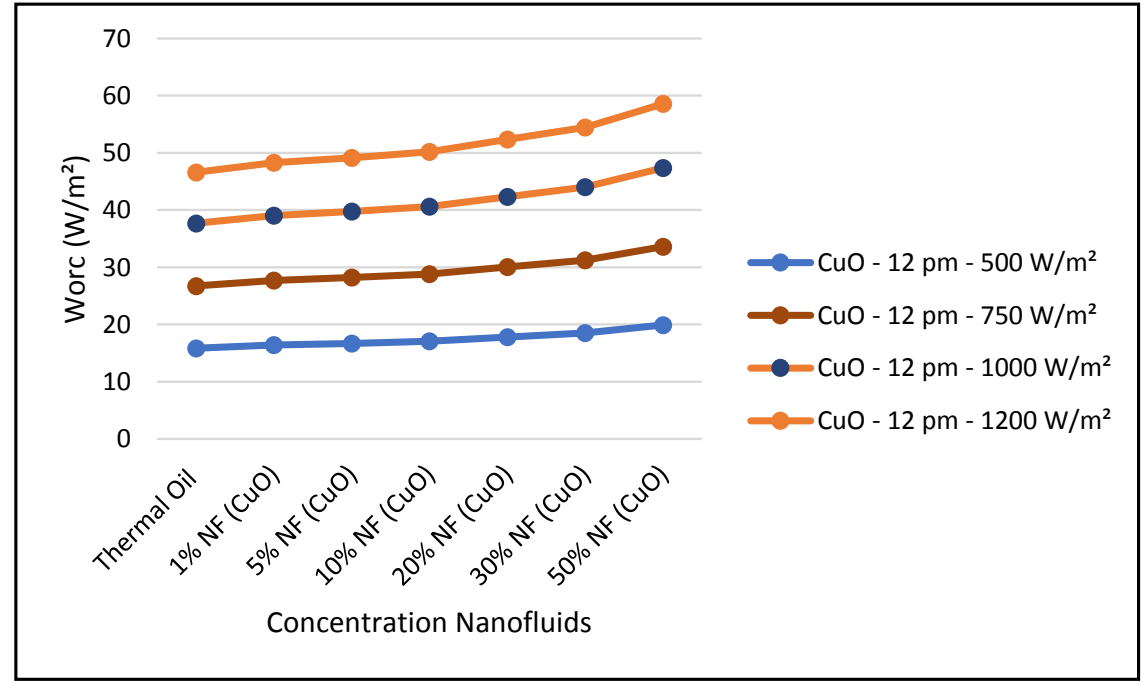

Figure 30. CSP system hybrid ORC work at $\mathrm{CuO}$ nanofluid and different concentrations.

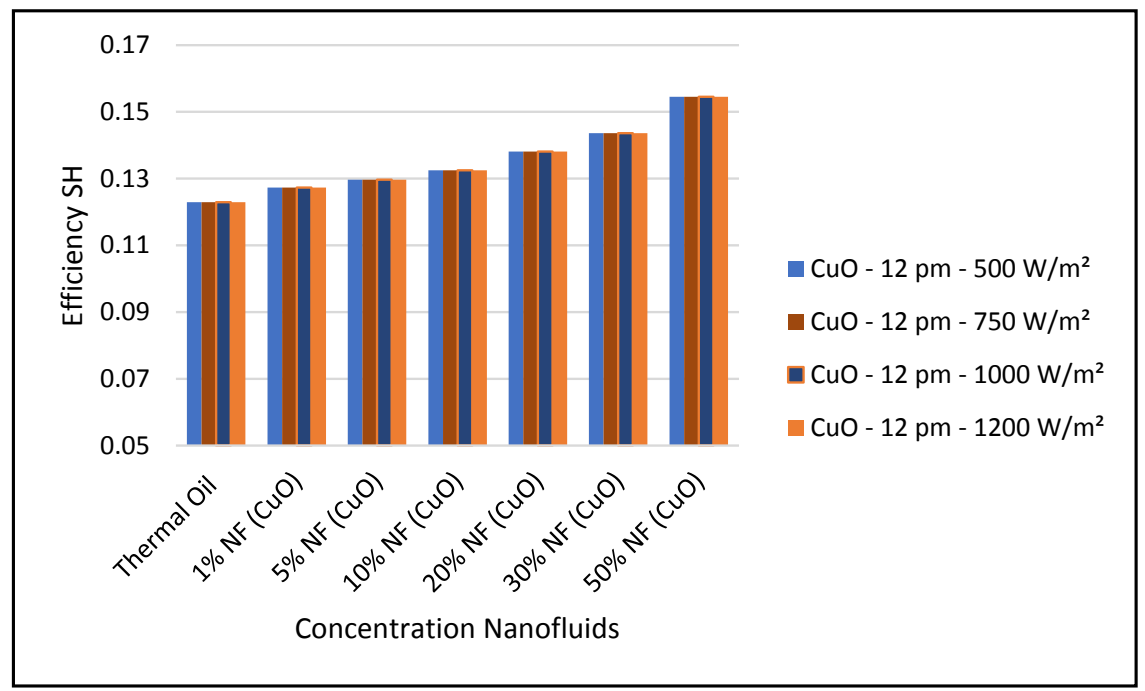

Figure 31. CSP system hybrid efficiency at $\mathrm{CuO}$ nanofluid and different concentrations. 


\section{Model Validation}

Among a few experimental data that have been reported in the literature on the use of nanofluids in CSP solar collectors, we compared the present model's prediction of the enhancement ratio of the ORC work produced due to the use of the nanofluids; $\mathrm{CuO}$ and $\mathrm{Al}_{2} \mathrm{O}_{3}$ with the data reported by Bellos and Tzivanidis [35]. This comparison is presented in Figures 32 and 33, under nanofluid concentrations of $1-6 \%$. The objective of their work was to optimize and evaluate a solar-driven trigeneration system that uses nanofluid-based parabolic trough solar collectors. The trigeneration system studied in reference [35] included an organic Rankine cycle (ORC) and an absorption heat pump operating with $\mathrm{LiBr}-\mathrm{H}_{2} \mathrm{O}$, which is powered by heat dissipated from condenser of the ORC. The comparison between the data of Bellos and Tzivanidis [35] and our model's prediction was conducted for the nanofluids $\mathrm{CuO}$ and $\mathrm{Al}_{2} \mathrm{O}_{3}$ on the basis of the enhancement of the work produced by the ORC with each nanofluid, respectively. It was found that the data and the model have the same trend; however, some discrepancies exit between the model's prediction and the experimental data. It is believed that the selection of the basic operating parameters: the pressure in the turbine inlet, the temperature in the ORC condenser and the nanofluid concentration attributed to the discrepancies between model's prediction and the data. In addition, reference [35] did not disclose the aforementioned parameters, which are critical in the validation of the current model. Therefore, other references were consulted [38-40].

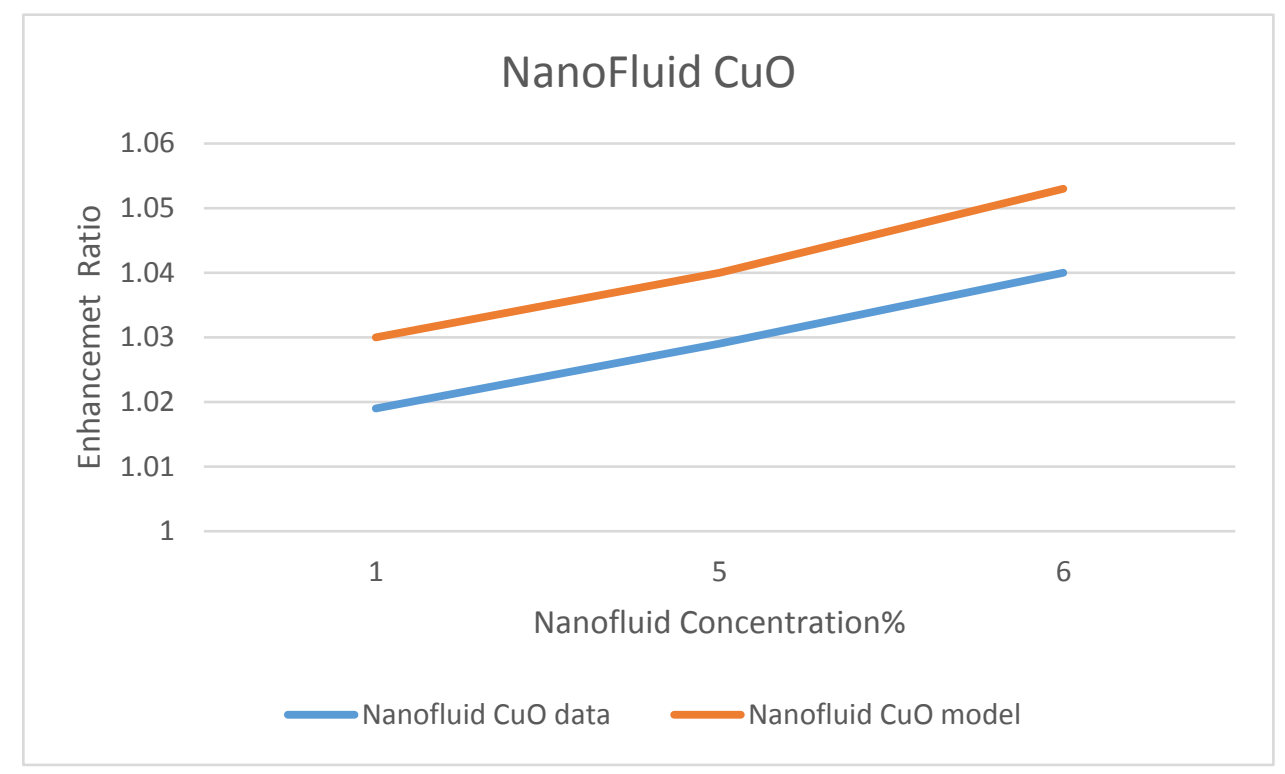

Figure 32. Comparison between model and data of Bellos and Tzivanidis [35].

Marefatoi et al. [31] presented an optical and thermal analysis of parabolic trough solar collector (PTC) and evaluated the performance of the PTC, using four cities with different weather conditions. The analysis was performed using MATLAB software and shows an average annual thermal efficiency of $13.91 \%$. Also, their work concluded that using the nanofluids $\mathrm{CuO}, \mathrm{SiO} 2$ and $\mathrm{Al}_{2} \mathrm{O}_{3}$ as heat transfer fluid increased the heat transfer and system efficiency under average solar radiations of $344 \mathrm{w} / \mathrm{m}^{2}$. Those results and conclusions were compared to our model's predictions under similar average solar radiations and it was found that our prediction of the system efficiency was, on average, $13.15 \%$, compared to $13.91 \%$ reported by reference [31]. In addition, our model predictions were in agreement with the results of reference [31] that nanofluids; $\mathrm{CuO}, \mathrm{SiO}_{2}$ and $\mathrm{Al}_{2} \mathrm{O}_{3}$ enhanced the heat transfer.

Other comparisons between our model's prediction for the convection heat transfer coefficient and the data reported by Marefatoi et al. [31] on $\mathrm{Al}_{2} \mathrm{O}_{3}$ and $\mathrm{SiO}_{2}$ are presented in Figures 34 and 35, respectively, at a solar radiation of $425 \mathrm{w} / \mathrm{m}^{2}$. The comparison displayed in these figures shows that as the nanofluid concentration increases the heat transfer coefficient increases. Our model compares fairly with the data of reference [31]; however, our model underpredicted the heat transfer coefficient by 
9.3\% and $8.8 \%$ for the nanofluids $\mathrm{Al}_{2} \mathrm{O}_{3}$ and $\mathrm{SiO}_{2}$, respectively. This could be attributed to the different relationships used to calculate the thermophysical properties of the nanofluids in question and used in the Dittus-Bölter correlation [36] to calculate the heat transfer coefficient.

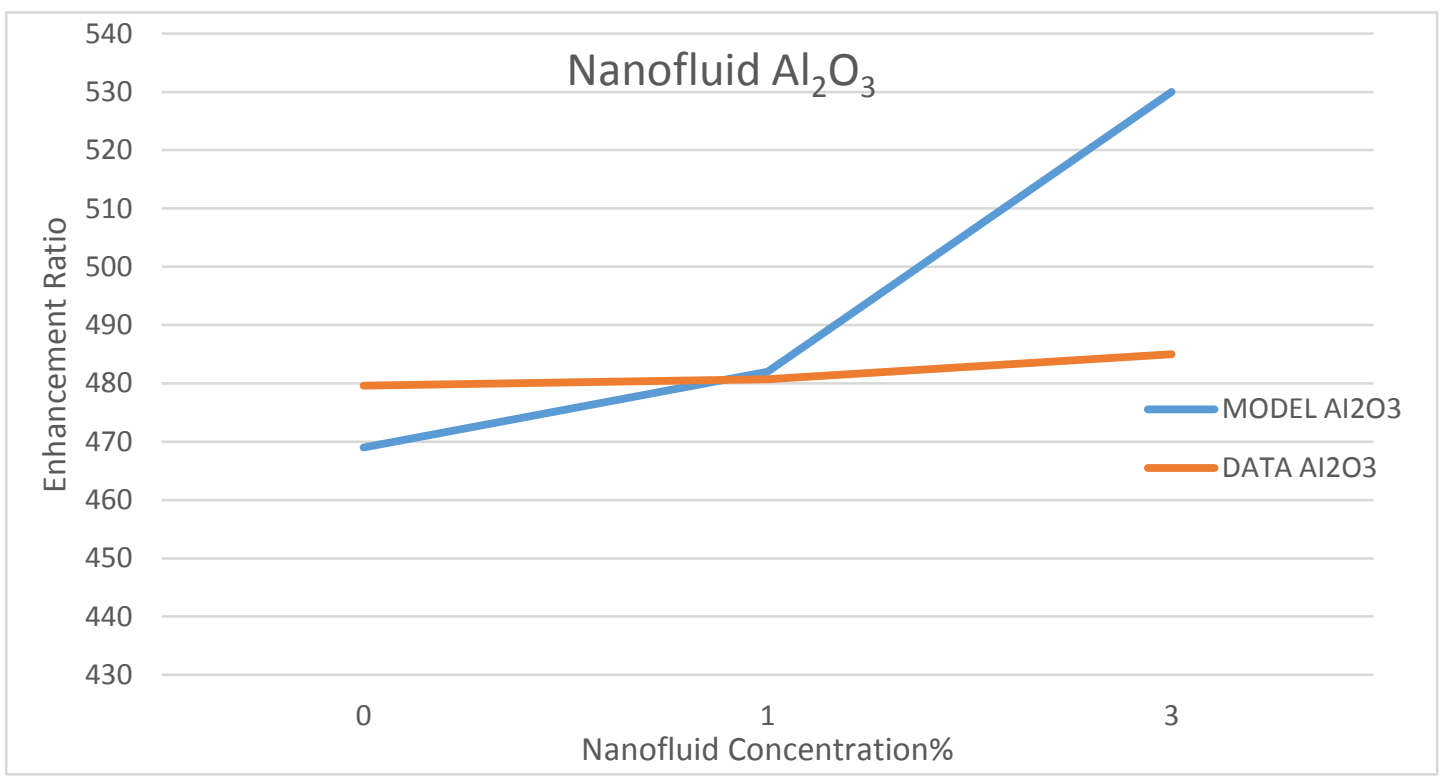

Figure 33. Comparison between model and data of Bellos and Tzivanidis [35] as in text is $\left(\mathrm{Al}_{2} \mathrm{O}_{3}\right)$ and applies to all other Figures.

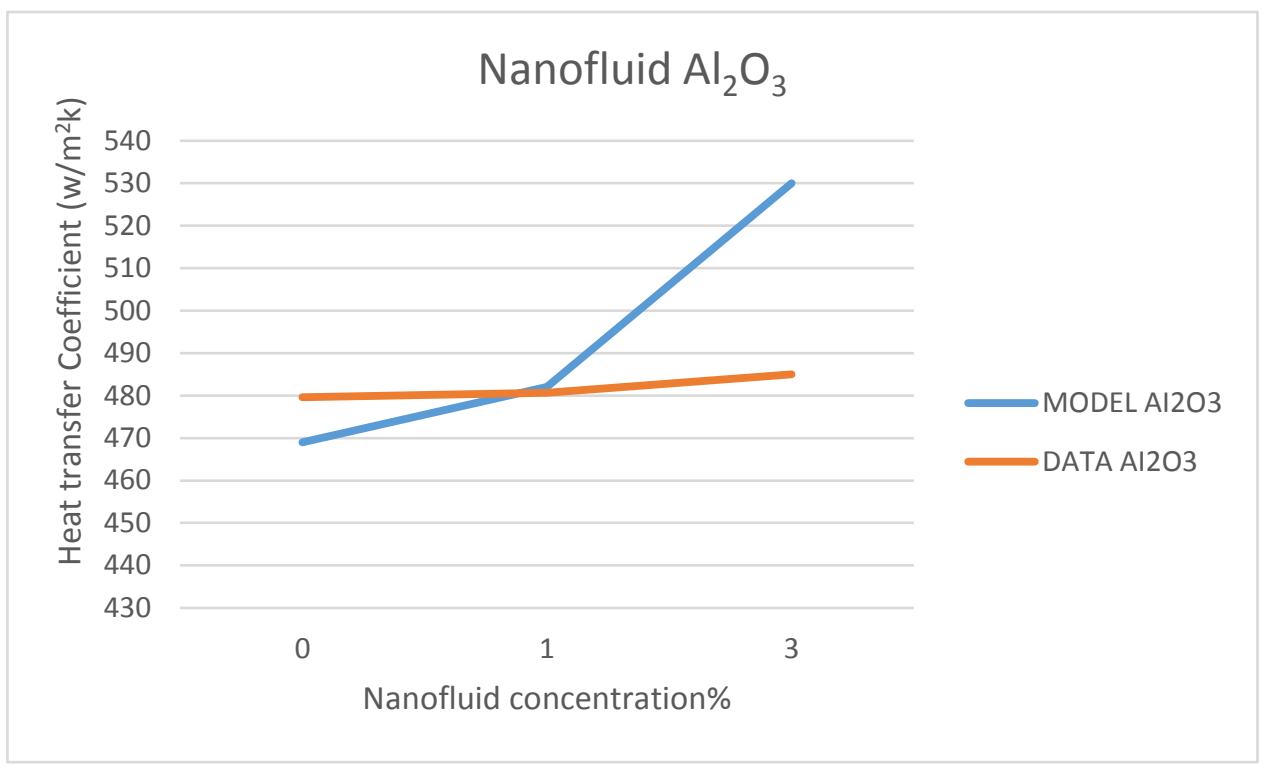

Figure 34. Comparison between model and data of Marefatoi et al. [31] for $\mathrm{Al}_{2} \mathrm{O}_{3}$ as in text is $\left(\mathrm{Al}_{2} \mathrm{O}_{3}\right)$ and applies to all other Figures. 


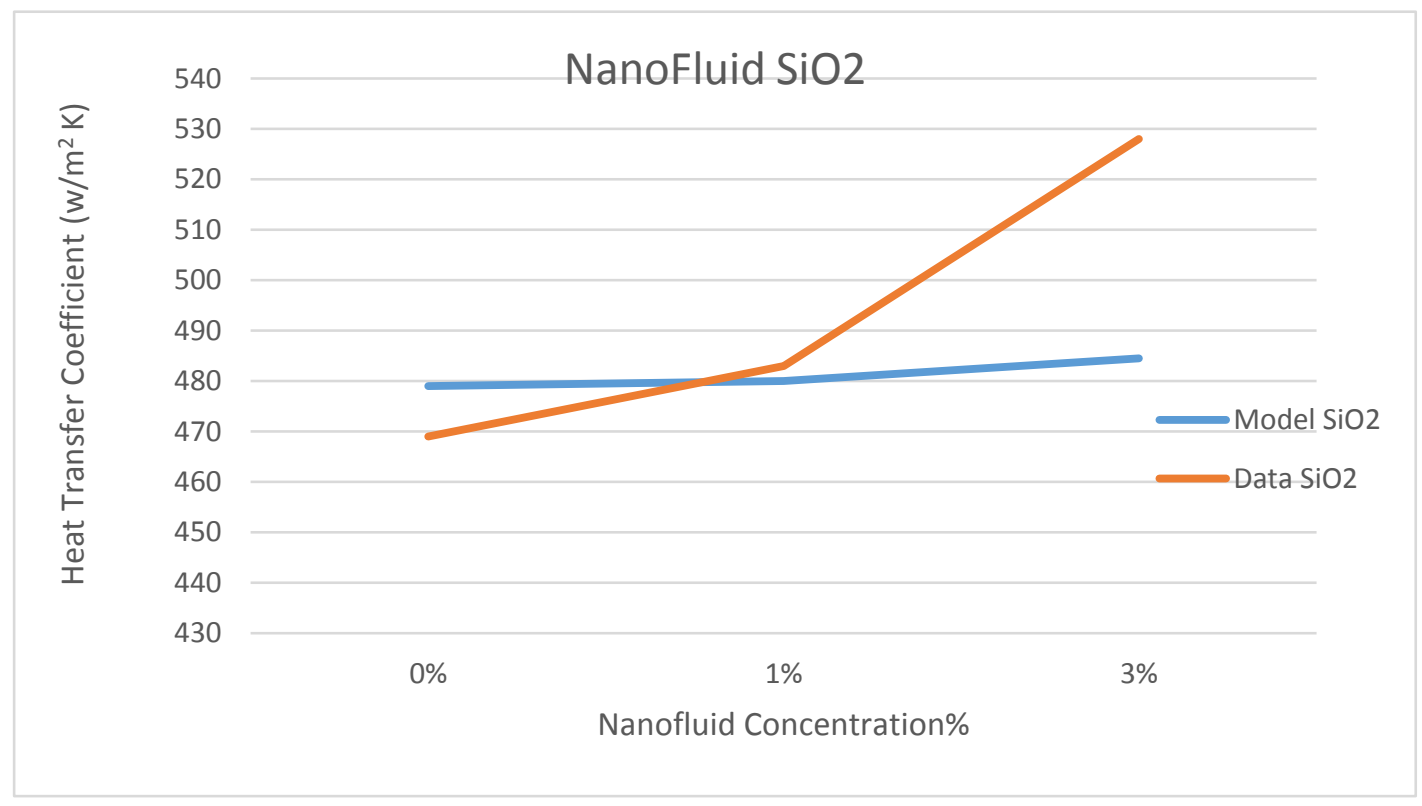

Figure 35. Comparison between model and data of Marefatoi et al. [31] for $\mathrm{SiO}_{2}$ as in text is $\left(\mathrm{Al}_{2} \mathrm{O}_{3}\right)$ and applies to all other Figures.

\section{Conclusions}

This study is intended to investigate the enhancement effect and characteristics of nanofluids $\mathrm{Al}_{2} \mathrm{O}_{3}, \mathrm{CuO}, \mathrm{Fe}_{3} \mathrm{O}_{4}$ and $\mathrm{SiO}_{2}$ in an integrated concentrating solar power (CSP) with ORC, and TES under different solar radiations, angle of incidence, and different nanofluids concentrations. During the course of this study, the results showed that the power absorbed, and power collected by the CSP collector, thermal energy stored in the storage tank and work produced by the ORC are enhanced with the increase of the solar radiation. The results of the efficiencies of the CSP and the hybrid system also showed clearly that the CSP efficiency is higher than the hybrid system efficiency and peaked at midday. It was also found that the CSP hybrid system efficiency was enhanced mainly by the increase of the solar radiation and higher nanofluid concentrations over the thermal oil as base fluid. As expected, the results indicate that the higher efficiencies of the hybrid system the higher the solar radiations, but the CSP collector efficiencies are independent of the nanofluid concentrations. In addition, the study concludes that the nanofluid $\mathrm{CuO}$ outperforms other nanofluids $\mathrm{Al}_{2} \mathrm{O}_{3}, \mathrm{Fe}_{3} \mathrm{O}_{4}$ and $\mathrm{SiO}_{2}$ and has the highest CSP solar collector performance compared to the other nanofluids and thermal oil base fluid under similar conditions. Finally, it was found that the model's prediction compares fairly with data reported in the literature; however, some discrepancies exit between the model's prediction and the experimental data. It is recommended that further experimental studies be conducted using nanofluids $\mathrm{Al}_{2} \mathrm{O}_{3}$ and $\mathrm{SiO}_{2}$ in the CSP solar collector loop to obtain more experimental data on the parameters; work enhancement ratios and heat transfer coefficient presented in the validation section under different solar radiation and heat transfer fluid different conditions. This should help to tune the model and improve the predicted results.

Funding: This research received no external funding.

Acknowledgments: The research work presented in this paper was made possible by the support of the Catholic University of Cuenca. 


\section{Nomenclature}

$\begin{array}{ll}A_{\text {aperture }} & \text { total aperture }\left(\mathrm{m}^{2}\right) \\ C_{\text {poil }} & \text { specific heat of thermal oil the base fluid. } \\ D N I & \text { Solar radiation }\left(\mathrm{w} / \mathrm{m}^{2}\right) \\ E_{l} & \text { End losses } \\ h_{1} & \text { enthalpy at the outlet of the waste heat boiler }(\mathrm{kj} / \mathrm{Kg}) \\ h_{2} & \text { enthalpy at the exit of the vapor turbine }(\mathrm{kj} / \mathrm{Kg}) \\ h_{3} & \text { enthalpy at the condenser outlet }(\mathrm{kj} / \mathrm{kg}) \\ h_{4} & \text { enthalpy at ORC pump outlet }(\mathrm{kj} / \mathrm{kg}) \\ m_{\text {ref }} & \text { refrigerant mass flow rate }(\mathrm{kg} / \mathrm{s}) \\ m_{\text {oil }} & \text { is the oil flow rate obtained from Equation }(8) \\ I A M & \text { incidence angle modifier. } \\ P_{\text {abs }} & \text { collector power absorbed by CSP defined in Equation }(1) \\ P_{\text {losscol }} & \text { collector thermal losses of the CSP. } \\ P_{\text {losspip }} & \text { solar field piping losses. } \\ R_{S} & \text { row shadow } \\ S F_{\text {Aval }} & \text { solar field available } \\ \text { Greek } & \\ \Theta & \text { angle of incidence } \\ \eta_{\text {opt }} & \text { optical efficiency } \\ \rho_{p} & \text { represents the density of the nanoparticle. }\end{array}$

\section{References}

1. Pavlović, T.M.; Radonjić, I.S.; Milosavljević, D.D.; Pantić, L.S. A review of concentrating solar power plants in the world and their potential use in Serbia. Renew. Sustain. Energy Rev. 2012, 16, 3891-3902. [CrossRef]

2. Ummadisingu, A.; Soni, M. Concentrating solar power-Technology, potential and policy in India. Renew. Sustain. Energy Rev. 2011, 15, 5169-5175. [CrossRef]

3. Izquierdo, S.; Montanes, C.; Dopazo, C.; Fueyo, N. Analysis of CSP plants for the definition of energy policies: The influence on electricity cost of solar multiples, capacity factors and energy storage. Energy Policy 2010, 38, 6215-6221. [CrossRef]

4. Solar PACES. CSP Projects around the World. 2016. Available online: http://www.solarpaces.org/csptechnology/csp-projects-around-the-world (accessed on 7 May 2016).

5. Mohamad, A.; Orfi, J.; Alansary, H. Heat losses from parabolic trough solar collectors. Int. J. Energy Res. 2014, 38, 20-28. [CrossRef]

6. Islama, M.T.; Hudaa, N.; Abdullah, A.B.; Saidur, R. A comprehensive review of state-of-the-art concentrating solar power (CSP), technologies: Current status and research trends. Renew. Sustain. Energy Rev. 2018, 91, 987-1018. [CrossRef]

7. Peters, M.; Schmidt, T.S.; Wiederkehr, D.; Schneider, M. Shedding light on solar technologies—A techno-economic assessment and its policy implications. Energy Policy 2011, 39, 6422-6439. [CrossRef]

8. Orosz, M.; Dickes, R. Organic Rankine Cycle (ORC) Power Systems, Technologies and Applications; Woodhead Publishing: Swanston, UK, 2017; pp. 569-612.

9. FreemanaI, J.; Guarracinoa, L.; Kalogiroub, S.A.; Markidesa, C.N. A small-scale solar organic Rankine cycle combined heat and power system with integrated thermal energy storage. Appl. Therm. Eng. 2017, 127, 1543-1554. [CrossRef]

10. Taylor, R.A.; Phelan, P.E.; Otanicar, T.P.; Walker, C.A.; Nguyen, M. Applicability of Nanofluids in High Flux Solar Collectors. J. Renew. Sustain. Energy 2011, 3, 023104. [CrossRef]

11. Nagarajan, P.K.; Subramani, J.; Suyambazhahan, S.; Ravishankar, S. Nanofluids for solar collector applications: A Review. Energy Procedia 2014, 61, 2416-2434. [CrossRef]

12. Francesco, C.; Laura, V. Parabolic Trough Photovoltaic/Thermal Collectors: Design and Simulation Model. Energies 2012, 5, 4186-4208. [CrossRef]

13. Navid, B.; Maryam, S. Performance evaluation of nanofluids in solar energy: A review of the recent literature. Nano Syst. Lett. 2015, 3, 5. [CrossRef] 
14. Donghyun, S.; Byeongnam, J.; Hyun-eun, K.; Debjyoti, B. Investigation of High Temperature Nanofluids for Solar Thermal Power Conversion and Storage Applications. In Proceedings of the 14th International Heat Transfer Conference, Washington, DC, USA, 8-13 August 2010; Volume 7, pp. 583-591, Paper No. IHTC14-23296. [CrossRef]

15. Lomascolo, M.; Colangelo, G.; Milanese, M.; de Risi, A. Review of heat transfer in nanofluids: Conductive, convective and radiative experimental results. Renew. Sustain. Energy Rev. 2015, 43, 1182-1198. [CrossRef]

16. Milanese, M.; Colangelo, G.; Cretì, A.; Lomascolo, M.; Iacobazzi, F.; de Risi, A. Optical absorption measurements of oxide nanoparticles for application as nanofluid in direct absorption solar power systems-Part II: $\mathrm{ZnO}$, $\mathrm{CeO} 2, \mathrm{Fe} 2 \mathrm{O} 3$ nanoparticles behavior. Sol. Energy Mater. Sol. Cells 2016, 147, 321-326. [CrossRef]

17. Iacobazzi, F.; Milanese, M.; Colangelo, G.; Lomascolo, M.; de Risi, A. An explanation of the $\mathrm{Al}_{2} \mathrm{O}_{3}$ nanofluid thermal conductivity based on the phonon theory of liquid. Energy 2016, 116, 786-794. [CrossRef]

18. Bahram, S.; Reza, F.; Torsten, F. Waste heat recovery Organic Rankine cycles in sustainable energy conversion: A state-of-the-art review. J. Macro Trends Energy Sustain. 2013, 1, 161-188.

19. Christos, T.; Bellos, E.; Antonopoulos, A. Energetic and financial investigation of a stand-alone solar-thermal Organic Rankine Cycle power plan. Energy Convers. Manag. 2016, 126, 421-433. [CrossRef]

20. Adnan, A.; Mohamed, G. Thermodynamic Analysis of a Parabolic Trough Solar Collector Power Generation Plant Coupled with an Organic Rankine Cycle. In Proceedings of the ASME 2018 12th International Conference on Energy Sustainability, Lake Buena Vista, FL, USA, 24-28 June 2018. [CrossRef]

21. Saloux, E.; Sorin, M.; Nesreddine, H.; Teyssedou, A. Thermodynamic Modeling and Optimal Operating Conditions of Organic Rankine Cycles (ORC) Independently of the Working Fluid. Int. J. Green Technol. 2019, 5, 9-22.

22. Sami, S.; Marin, E. A Numerical Model for Predicting Dynamic Performance of Biomass-Integrated Organic Rankine Cycle, ORC, System for Electricity Generation. AJEE Am. J. Energy Eng. 2016, 4, 26-33. [CrossRef]

23. Sami, S.M. Behavior of orc low temperature power generation with different refrigerants. Int. J. Ambient Energy 2011, 32, 37-45. [CrossRef]

24. Jo ao, P.S.; Rui, C. Modeling and Simulation of a Parabolic Trough Power Plant. Green 2012, 2, 97-104. [CrossRef]

25. Sharma, K.V.; Akilu, S.; Hassan, S.; Hegde, G. Considerations on the Thermophysical Properties of Nanofluids. In Engineering Applications of Nanotechnology, Topics in Mining, Metallurgy and Materials Engineering; Springer: Berlin, Germany, 2017.

26. Sami, S. Impact of magnetic field on the enhancement of performance of thermal solar collectors using nanofluids. Int. J. Ambient Energy 2019, 40, 1-10. [CrossRef]

27. Standard Reference Data. 2013. Available online: https://www.nist.gov/srd/refprop (accessed on 14 July 2019).

28. Boonrit, P. Efficiency improvement of a concentrated solar receiver for water heating system using porous medium. IOP Conf. Ser. Mater. Sci. Eng. 2017, 297, 012059. [CrossRef]

29. Sami, S.; Marin, E. Modelling and Simulation of PV Solar-Thermoelectric Generators using Nano fluids. Int. J. Sustain. Energy Environ. Res. 2019, 8, 10-28. [CrossRef]

30. Xiaoming, Z.; Yuting, W.; Chongfang, M.; Qiang, M.; Xiao, H.; Cenyu, Y. Experimental Study on Temperature Distribution and Heat Losses of a Molten Salt Heat Storage Tank. Energies 2019, 12, 1943. [CrossRef]

31. Mohammad, S.B.; Mehdi, M.; Maryam, M. Optical and thermal analysis of a parabolic trough solar collector for production of thermal energy in different climates in Iran with comparison between the conventional nanofluids. J. Clean. Prod. 2018, 175, 294-313.

32. Ruiqi, W.; Long, J.; Zhiwei, M.; Gonzalez-Diaz, A.; Yaodong, W.; Roskilly, A.P. Comparative Analysis of Small-Scale Organic Rankine Cycle Systems for Solar Energy Utilisation. Energies 2019, 12, 829. [CrossRef]

33. Rémi, D.; Olivier, D.; Sébastien, D.; Sylvain, Q.; Ian, B. Vincent, Experimental investigation of an ORC system for a micro-solar power plant. In Proceedings of the 22nd International Compressor Engineering Conference at Purdue, Red Hook, NY, USA, 14-17 July 2014; pp. 1-10.

34. Bahram, S.; Reza, F.; Torsten, F. Conceptual modeling of nano fluid ORC for solar thermal polygeneration. Energy Procedia 2014, 57, 2696-2705.

35. Evangelos, B.; Christos, T. Optimization of a Solar-Driven Trigeneration System with Nanofluid-Based Parabolic Trough Collectors. Energies 2017, 10, 848. [CrossRef]

36. Incropera, F.; DeWitt, D. Fundamentals of Heat and Mass Transfer, 4th ed.; Wiley: New York, NY, USA, 1994; p. 493. ISBN 978-0-471-30460-9. 
37. Heat Transfer Fluid-Dow Chemical. Available online: https://www.dow.com/webapps/lit/litorder.asp? filepath=/heattrans/pdfs/noreg/176 (accessed on 16 July 2019).

38. Xu, Z.Y.; Wang, R.Z.; Wang, H.B. Experimental evaluation of a variable effect LiBr-water absorption chiller designed for high-efficient solar cooling system. Int. J. Refrig. 2015, 59, 135-143. [CrossRef]

39. Bellos, E.; Tzivanidis, C.; Antonopoulos, K.A. Exergetic, energetic and fine evaluation of a solar driven absorption cooling system with various collector types. Appl. Therm. Eng. 2016, 102, 749-759. [CrossRef]

40. F-Chart Software, Engineering Equation Solver (EES). 2015. Available online: http://www.fchart.com/ees/ (accessed on 16 July 2019).

(C) 2019 by the author. Licensee MDPI, Basel, Switzerland. This article is an open access article distributed under the terms and conditions of the Creative Commons Attribution (CC BY) license (http://creativecommons.org/licenses/by/4.0/). 